\title{
Distinct cellular phenotype linked to defective DNA interstrand crosslink repair and homologous recombination
}

\author{
ALEKSANDRA M. GORNIEWSKA ${ }^{1 *}$, KATARZYNA KLUZEK ${ }^{2}$, LIDIA GACKOWSKA ${ }^{3}$, \\ IZABELA KUBISZEWSKA $^{3}$, MALGORZATA Z. ZDZIENICKA $^{1 * *}$ and ANETA BIALKOWSKA ${ }^{4 *}$ \\ ${ }^{1}$ Collegium Medicum in Bydgoszcz, Nicolaus Copernicus University in Torun, Bydgoszcz 85-094; \\ ${ }^{2}$ Department of Human Molecular Genetics, Adam Mickiewicz University, Poznan 61-614; \\ ${ }^{3}$ Department of Immunology, Collegium Medicum in Bydgoszcz, Nicolaus Copernicus University in Torun, \\ Bydgoszcz 85-094; ${ }^{4}$ Innovative Medical Forum, Franciszek Lukaszczyk Oncology Center, Bydgoszcz 85-796, Poland
}

Received March 23, 2016; Accepted March 29, 2017

DOI: $10.3892 / \mathrm{mmr} .2017 .6781$

\begin{abstract}
Repair of DNA interstrand crosslinks (ICLs) predominantly involves the Fanconi anemia (FA) pathway and homologous recombination (HR). The HR repair system eliminates DNA double strand breaks (DSBs) that emerge during ICLs removal. The current study presents a novel cell line, CL-V8B, representing a new complementation group of Chinese hamster cell mutants hypersensitive to DNA crosslinking factors. CL-V8B exhibits increased sensitivity to various DNA-damaging agents, including compounds leading to DSBs formation (bleomycin and 6-thioguanine), and is extremely sensitive to poly (ADP-ribose) polymerase inhibitor (>400-fold), which is typical for HR-defective cells. In addition, this cell line exhibits a reduced number of spontaneous and induced sister chromatid exchanges, which suggests likely impairment of HR in CL-V8B cells. However, in contrast to other known HR mutants, CL-V8B cells do not show defects in Rad51 foci induction, but only slight alterations in the focus formation kinetics. CL-V8B is additionally characterized by a considerable chromosomal instability, as indicated by a high number of spontaneous and MMC-induced chromosomal aberrations, and a twice as large proportion of cells with abnormal centrosomes than that in the wild type cell line. The molecular defect present in CL-V8B does not affect the efficiency and stabilization of replication forks. However, stalling of the forks in response to replication stress is observed relatively rarely, which suggests an impairment of a signaling mechanism.
\end{abstract}

Correspondence to: Dr Aneta Bialkowska, Innovative Medical Forum, Franciszek Lukaszczyk Oncology Center, Dr I. Romanowskiej 2, Bydgoszcz 85-796, Poland

E-mail: anetabial@yahoo.com

${ }^{*}$ Contributed equally

***Deceased

Key words: Chinese hamster mutant, interstrand crosslinks, DNA repair, homologous recombination, Fanconi anemia pathway
Exposure of CL-V8B to crosslinking agents results in S-phase arrest (as in the wild type cells), but also in larger proportion of $\mathrm{G}_{2} / \mathrm{M}$-phase cells and apoptotic cells. CL-V8B exhibits similarities to HR- and/or FA-defective Chinese hamster mutants sensitive to DNA crosslinking agents. However, the unique phenotype of this new mutant implies that it carries a defect of a yet unidentified gene involved in the repair of ICLs.

\section{Introduction}

Chinese hamster cell mutants, obtained by chemical mutagenesis of wild type cells from the lung or ovary, have served as a valuable model in research on various biological processes in eukaryotes. At present, despite the expansion of numerous novel molecular techniques, such as gene silencing and the use of transgenic animals, Chinese hamster cell mutants remain to serve a significant role, particularly in the research of novel therapeutic strategies and drug resistance mechanisms in cancer cells (1-3). It has been established that fibroblast cell lines sensitive to various carcinogenic agents are used as a basic tool, contributing to the identification of numerous genes involved in various DNA repair pathways. UVC-sensitive Chinese hamster cell lines have been used to identify more than a half of nucleotide excision repair (NER) genes, including excision repair cross-complementation group 1 (Erccl), Ercc2 [Xeroderma pigmentosum complementary group $\mathrm{D}(X P D)$ in humans], Ercc3 $(X P B), \operatorname{Ercc} 4$ [(XPF/Fanconi anemia (FA) complementation group Q $(F A N C Q)], \operatorname{Ercc5}(X P G)$ and Ercc6 (Cockayne syndrome B protein, $C S B$ ) $(4,5)$. In addition, genes involved in other DNA repair pathways, e.g. base excision repair (X-ray repair complementing defective repair in Chinese hamster cells 1, Xrccl), homologous recombination (Xrcc2 and $X r c c 3)$ and non-homologous end joining [Xrcc4, Xrcc5/KU80, $X r c c 7 /$ protein kinase, DNA-activated, catalytic polypeptide $(P R K D C)$ ] were identified during the studies of the ionizing radiation-sensitive mutants (6). The cellular phenotype determined by mutations in Erccl and Rad51c/Fanco repair genes was described before identification of patients with these lesions (7-9). Due to phenotypic similarity between Chinese hamster cell mutants sensitive to various DNA-damaging agents and the cells of patients whose diseases are associated 
with abnormal DNA repair (including ataxia-telangiectasia, Xeroderma pigmentosum or FA), rodent mutants remain as a useful model for studying mechanisms of DNA repair $(10,11)$.

While the majority of repair mechanisms are relatively well known, ICLs removal remains to be fully understood. These highly toxic lesions are introduced to DNA by crosslinking agents, including derivatives of nitrogen mustard, platinum compounds e.g. cisplatin (CDDP), mitomycin C (MMC) and psoralens, which are commonly used in the treatment of various malignancies (12). Removal of ICLs is a complicated process involving proteins from the majority of the known DNA repair pathways. The process can be simplified to three main steps: i) Cell cycle arrest induced by the presence of ICLs within DNA and recruitment of DNA repair proteins, depending primarily on the FA pathway and ataxia telangiectasia and Rad3-related protein (ATR), ii) excision of ICLs from DNA with the participation of NER- and FA-associated proteins, which leads to formation of DNA double strand breaks (DSBs), and iii) repair of DSBs by homologous recombination (12).

Defective ICLs repair has been observed in several human hereditary diseases associated with genetic instability, predominantly in FA, however additionally in Xeroderma pigmentosum, cerebro-oculo-facio-skeletal syndrome (COFS), Roberts syndrome, Cornelia de Lange syndrome and Warsaw breakage syndrome (13-16). In addition, heterozygous mutations of FA genes, namely breast cancer 2, early onset (BRCA2; also referred to as FANCD1), BRCA1 interacting protein C-terminal helicase 1 (BRIP1, also termed $F A N C J)$, partner and localizer of BRCA2 (PALB2, also termed $F A N C N$ ) and $R A D 51 C / F A N C O$, may predispose to cancer, in particular to breast and/or ovarian malignancies (17). Despite major progress in research on ICLs repair, the molecular backgrounds of FA and Cornelia de Lange syndrome remain unclear in 5 and $35 \%$ of patients with these conditions, respectively (http://fanconi.org) (18). This in turn implies that certain genes involved in ICLs removal remain to be identified.

A total of 8 complementation groups of Chinese hamster cell mutants sensitive to DNA crosslinking agents, carrying mutations of Ercc1, Ercc4, Xrcc2, Xrcc3, Brca2, Rad51C, Fanca and Fancg genes, have been described at present (4,6-8,19-22). The current study demonstrated a novel Chinese hamster mutant, CL-V8B, with an unknown genetic background and different phenotype than that identified in previously described cell lines hypersensitive to DNA crosslinking agents. CL-V8B cells share numerous features of HR mutants, which points to the likely role of mutated genes in this DNA repair process.

\section{Materials and methods}

Cell lines and culture conditions. Cell lines and hybrids used in the present study were provided by the Department of Toxicogenetics, Leiden University Medical Centre, The Netherlands. Wild type and chemically (N-ethyl-N-nitrosourea, ENU) mutated fibroblasts of Chinese hamster were routinely cultured in 94-mm culture dishes (Greiner Bio-One International GmbH, Kremsmünster, Austria) in Ham's F10 medium (Sigma-Aldrich; Merck Millipore, Darmstadt, Germany) supplemented with $10 \%$ fetal calf serum (Gibco; Thermo Fisher Scientific, Inc., Waltham, MA, USA) and antibiotics (penicillin $1 \mathrm{U} / \mathrm{ml}$, streptomycin $0.1 \mathrm{mg} / \mathrm{ml}$; Sigma-Aldrich; Merck Millipore). The cells were maintained at $37^{\circ} \mathrm{C}$ in a $5 \% \mathrm{CO}_{2}$ atmosphere and relative humidity of $95 \%$. The cells for subcultures were washed in phosphate-buffered saline (PBS; Sigma-Aldrich; Merck Millipore) and detached with $0.25 \%$ trypsin containing $1 \mathrm{mM}$ EDTA (Sigma-Aldrich; Merck Millipore). The cells were stored at $-85^{\circ} \mathrm{C}$ in ampules (Nunc; Thermo Fisher Scientific, Inc.) containing 1x10 cells in Ham's F10 medium with the addition of $6 \%$ dimethyl sulfoxide (DMSO; Sigma-Aldrich; Merck Millipore). Prior to the experiment, the cells were taken from ampules, seeded for 2 days, then subcultured and grown for another 2 days. The study was approved by the Ethics Committee of the Collegium Medicum in Bydgoszcz, Poland.

Clonogenic survival assay. To establish the sensitivity of CL-V8B to bleomycin (BLM; Dagra Pharma B.U., Diemen, Netherlands), camptothecin (CPT; Sigma-Aldrich; Merck Millipore), CDDP (Sigma-Aldrich; Merck Millipore), hydroxyurea (HU; Sigma-Aldrich; Merck Millipore), hydrogen peroxide $\left(\mathrm{H}_{2} \mathrm{O}_{2}\right.$; Merck Millipore), PARP inhibitor KU0058948 (donated by Dr Graeme C. M. Smith; KuDOS Pharmaceuticals Limited; Astra Zeneca), MMC (Kyowa Hakko Co., Ltd., Tokyo, Japan) and ultraviolet radiation (UVC light of $254 \mathrm{~nm}$; Philips Lamp, $6 \mathrm{~W}$ ), cell cultures in the exponential growth phase were trypsinized and then 300 cells were plated onto culture dishes in duplicate (untreated controls in triplicate). The cells were treated continuously with BLM, CPT, CDDP, HU, KU0058948 and MMC. In assays with CPT and KU0058948, these two reagents were dissolved in DMSO, the concentration of the latter in all plates, including the controls, was maintained at $0.5 \%$. Prior to $\mathrm{H}_{2} \mathrm{O}_{2}$ treatment and UVC exposure, the cells were allowed to attach for $4 \mathrm{~h}$ and then were incubated with $\mathrm{H}_{2} \mathrm{O}_{2}$ for $1 \mathrm{~h}$ or were irradiated. The dose of radiation was determined with the VLX 254 radiometer (Vilber Lourmat Deutschland GmbH, Eberhardzell, Germany). Subsequently, the cells were washed with PBS, and fresh growth medium was added. The cells were grown for 8-10 days, and then the dishes were rinsed with $0.9 \% \mathrm{NaCl}$ (Sigma-Aldrich; Merck Millipore), dried, stained with $0.25 \%$ methylene blue (Sigma-Aldrich; Merck Millipore) and dried again prior to counting the visible colonies. Parental cells used as the controls were treated in the same manner as the mutant cells. Survival curves were prepared with GraphPad Prism 5.0 software (GraphPad Software, Inc., La Jolla, CA, USA). Each survival curve illustrated a percentage of surviving cells as a function of the analyzed compound concentration or UVC dose. Cellular sensitivity was expressed as the $D_{10}$ value, i.e. the concentration of a chemical agent or the irradiation dose necessary to reduce the number of surviving cells to $10 \%$.

Genetic complementation analysis by cell fusion. Cell fusion was achieved with polyethylene glycol (PEG; Sigma-Aldrich; Merck Millipore), as previously described (23). Briefly, a total of $2 \times 10^{6}$ cells (1:1 ratio of each type) were seeded and incubated overnight in Ham's F10 medium. Then, the cells were rinsed with the serum-deprived medium and exposed for $1 \mathrm{~min}$ to $2 \mathrm{ml}$ fusion medium containing 47\% PEG and $10 \%$ DMSO. Subsequently, the cells were washed 3 times with the growth medium and incubated for $24 \mathrm{~h}$ to form hybrids. 
Then, the cells were trypsinized and plated ( 2 replicates from each cross) into hypoxanthine-aminopterin-thymidine (HAT) medium containing $1 \mathrm{mM}$ ouabain (Sigma-Aldrich; Merck Millipore). The populations of hybrid clones ( $>100)$ were then collected from each cross and subjected to genetic complementation analysis (correction of MMC sensitivity) with a clonogenic survival assay.

Analysis of chromosomal aberrations and sister chromatid exchanges. Chromosomal aberrations (CAs) and frequencies of sister chromatid exchanges (SCEs) were determined in exponentially growing cells. The cells for CAs determination were treated with various concentrations of MMC for $2 \mathrm{~h}$ (V79B: 25, 45 and $70 \mathrm{ng} / \mathrm{ml}$; CL-V8B: 1.5, 2.5 and $5 \mathrm{ng} / \mathrm{ml}$ ), and the cells for SCEs number determination were irradiated with UVC at a dose rate of $2.5,5$ and $10 \mathrm{~J} / \mathrm{m}^{2}$ or exposed to MMC (V79B: 15, $30 \mathrm{ng} / \mathrm{ml}$; Cl-V8B: 1, $1.5 \mathrm{ng} / \mathrm{ml}$ ), also for 2 h. Subsequently, $10 \mu \mathrm{M}$ 5-bromo-2'-deoxyuridine (BrdU; Sigma-Aldrich; Merck Millipore) was added to both the CAs and SCEs cultures. A total of $16 \mathrm{~h}$ (CAs) or $30 \mathrm{~h}$ (SCEs) subsequent to exposure of cells to MMC or UVC, colcemid (1 $\mu \mathrm{g} / \mathrm{ml}$; Sigma-Aldrich; Merck Millipore) was added to the growth medium for $2 \mathrm{~h}$. Following this, the cells were harvested, treated with hypotonic solution of $0.075 \mathrm{M} \mathrm{KCl}$ (Sigma-Aldrich; Merck Millipore) for $20 \mathrm{~min}$ at $37^{\circ} \mathrm{C}$ and fixed three times with methanol (Sigma-Aldrich; Merck Millipore)/glacial acid (Avantor Performance Materials Poland, Gliwice, Poland) solution (3:1 ratio). Air-dried slides were washed with $10 \mu \mathrm{M}$ bisbenzamide (Sigma-Aldrich; Merck Millipore) in the dark for $20 \mathrm{~min}$, incubated with McIlvaine citrate/phosphate buffer ( $\mathrm{pH} \mathrm{8;} \mathrm{Avantor} \mathrm{Performance} \mathrm{Mate-}$ rials Poland) using a slide drying hotplate $\left(60^{\circ} \mathrm{C}\right.$; Barnstead Electrothermal; Thermo Fisher Scientific, Inc.) exposed to UVC (Philips Lamp, $15 \mathrm{~W}$ ) for $25 \mathrm{~min}$ and stained with $10 \%$ Giemsa solution (NBS Biologicals, Huntingdon, UK). For CAs, 100 mitotic cells were analyzed for each MMC dose and for each experiment separately, and 30 cells were used for SCEs.

Immunofluorescence labelling and microscopy. To examine centrosomes and Rad51 focus formation, the cells were seeded onto 15-mm round coverslips (Menzel Gläser, Braunschweig, Germany). A total of $24 \mathrm{~h}$ after the seeding, the cells were washed with PBS and fixed on ice with methanol/acetone solution (7:3 ratio; Sigma Aldrich; Merck Millipore) for $15 \mathrm{~min}$ for centrosome analysis. The cells for determination of Rad51 foci were treated with equitoxic doses of MMC (V79 and V79B: $45 \mathrm{ng} / \mathrm{ml}$; CL-V8B: $2 \mathrm{ng} / \mathrm{ml}$; V-C8: 0,5 ng/ml) or BLM $(0.4 \mu \mathrm{g} / \mathrm{ml})$ for $1 \mathrm{~h}$ and then transferred again to Ham's F10 medium. At the indicated time points $(8,24,48$ and $56 \mathrm{~h})$ after the MMC or BLM treatment, the cells were washed and fixed in $2 \%$ formaldehyde (MP Biomedicals LLC, Solon, OH, USA) for $15 \mathrm{~min}$. Then, the cells were permeabilized with $0.1 \%$ Triton X-100 (MP Biomedicals LLC) and blocked for $30 \mathrm{~min}$ with PBS (PBS+) containing $0.15 \%$ glycine and $0.5 \%$ bovine serum albumin (Sigma-Aldrich; Merck Millipore). For centrosome analysis, all the stages mentioned above were held on ice. Subsequently, the cells were incubated for $1.5 \mathrm{~h}$ with mouse monoclonal antibodies against $\gamma$-tubulin (dilution 1:1,000; T655T; GTU-88 clone; Sigma-Aldrich; Merck Millipore) or rabbit polyclonal antibodies against $\operatorname{Rad} 51$ (2307; donated by
Dr Fiona Benson; Department of Public Health, Academic Medical Center, University of Amsterdam, Amsterdam, The Netherlands), washed with $0.1 \%$ Triton X-100 and PBS+, and incubated for $1 \mathrm{~h}$ with Alexa-488 conjugated polyclonal goat antibodies against mouse (R37120) or rabbit (A-11070) IgG (dilution 1:1,500; Molecular Probes Life Technologies; Thermo Fisher Scientific, Inc.). Then, the cells were washed again with $0.1 \%$ Triton $\mathrm{X}-100$ and their nuclei were stained with 4',6-diamino-2-phenylindole $(0.15 \mu \mathrm{g} / \mathrm{ml}$; Sigma-Aldrich; Merck Millipore). Subsequently, the round coverslips were coated with AquaPoly/Mount (Polysciences, Inc., Warrington, PA, USA), placed on standard glass slides (Menzel Gläser) and stored at $4^{\circ} \mathrm{C}$ in the dark. In each out of the three independent experiments, a total of 100 or 300 cells were examined under Nikon Eclipse E800 fluorescence microscope (Nikon Corporation, Tokyo, Japan) for the presence of centrosomes or Rad51 foci, respectively. The cells with more than five Rad51 foci per nucleus were considered as representing an active DNA repair process.

DNA fiber assay. Exponentially growing cells were labeled with 5-iodo-2'-deoxyuridine (50 $\mu \mathrm{M}$; IdU; Sigma-Aldrich; Merck Millipore) for $20 \mathrm{~min}$, and then exposed to hydroxyurea $(4 \mathrm{mM})$ for $1.5 \mathrm{~h}$. Subsequently, the cells were washed 3 times with PBS and a fresh growth medium containing 5-chloro 2'-deoxyuridine (50 $\mu \mathrm{M}$; CldU; Sigma-Aldrich; Merck Millipore) was added for $20 \mathrm{~min}$. To examine unperturbed replication, the HU exposure stage was omitted in the controls. DNA fibers were prepared as described previously, with certain modifications (24). Subsequent to labeling, the cells were trypsinized, centrifuged at room temperature for $10 \mathrm{~min}$ at $175.5 \mathrm{x} \mathrm{g}$ and resuspended in ice-cold PBS to obtain a concentration of $0.75 \times 10^{6}$ cells per ml. Subsequently, $2 \mu \mathrm{l}$ suspension was dropped on a glass slide, left for $2 \mathrm{~min}$ and mixed with $8 \mu 1$ lysis buffer (50 mM EDTA, $0.5 \%$ sodium lauryl sulfate, $200 \mathrm{mM}$ Tris-HCl; Sigma-Aldrich; Merck Millipore). Then, the slides were carefully tilted to a $45^{\circ}$ angle to allow the DNA fibers to spread. Subsequently, the slides were air-dried, fixed with methanol/glacial acid solution (3:1 ratio) for $10 \mathrm{~min}$, washed with $\mathrm{dH}_{2} \mathrm{O}$ and left overnight at $4^{\circ} \mathrm{C}$. Next day, the slides were treated with $2.5 \mathrm{M} \mathrm{HCl}$ (Merck Millipore) for $90 \mathrm{~min}$, washed in PBS and blocked for $1 \mathrm{~h}$ with 5\% BSA in PBS containing 0.1\% Triton X-100. Then, the slides were incubated with a mixture of primary $\alpha$-BrdU mouse (dilution 1:25; 347580; BD Biosciences, San Jose, CA, USA) and rat antibodies (dilution 1:400; ab6326; Abcam, Cambridge, MA, USA) for $2 \mathrm{~h}$, washed and incubated with secondary antibodies: Alexa-488 conjugated goat antibodies against mouse (1:200; R37120) and Alexa-555 conjugated goat antibodies against rat (1:350; A-21434) from Molecular Probes Life Technologies for $1 \mathrm{~h}$. DNA fibers were examined under the Nikon Eclipse E800 fluorescence microscope. A minimum of 150-200 individual fibers were analyzed for each experiment (repeated three times) using ImageJ software, version 1.49 (National Institutes of Health, Bethesda, MD, USA). The frequencies of various classes of replication structures were expressed as the percentages of all counted structures. Fork velocity was determined on the basis of the conversion factor $(1 \mu \mathrm{m}=2.59 \mathrm{~kb})$ established by Jackson and Pombo (24). 
Cell cycle analysis by flow cytometry. Cells from the exponential growth phase were exposed to MMC (50 and $250 \mathrm{ng} / \mathrm{ml}$ ) for 8,24 and $48 \mathrm{~h}$. Then, the cells were trypsinized, centrifuged, washed with PBS and centrifuged again. Subsequently, approximately $1-2 \times 10^{6}$ cells were stained with a solution of propidium iodide (50 $\mu \mathrm{g} / \mathrm{ml}$; Sigma-Aldrich; Merck Millipore) and $0.03 \%$ Nonidet P-40 (Sigma-Aldrich; Merck Millipore) for $15 \mathrm{~min}$ at room temperature in the dark, and incubated with RNAse A (100 $\mu \mathrm{g} / \mathrm{ml}, 88$ Kunitz U/ml; Sigma-Aldrich; Merck Millipore) under the same conditions. The number of cells from sub- $\mathrm{G}_{1}, \mathrm{G}_{0} / \mathrm{G}_{1}, \mathrm{~S}$ and $\mathrm{G}_{2} / \mathrm{M}$ phases was determined on the basis of their DNA contents, using FACS Canto II flow cytometer (BD Biosciences). The results were analyzed with FlowJo software, version 7.5.5 (Tree Star LLC, Ashland, OR, USA). Each experiment was repeated independently 3 times.

Statistical analysis. Statistical analysis was conducted with Statistica package (version 12; StatSoft Polska Sp. z o.o., Kraków, Poland). The descriptors of cell cycle distribution (percentages of cells from various cell cycle phases) at three time points $(8,24$ and $48 \mathrm{~h}$ ) were subjected to univariate one-way analysis of variance with repeated measures (dose 0 , 50 and $250 \mathrm{ng} / \mathrm{ml}$ ), followed by post hoc analysis with the least significant difference test. The results are presented as the means of biological replicates with their standard errors unless otherwise specified. All graphs and figures were prepared with GraphPad Prism 5.0 software (GraphPad Software Inc., La Jolla, CA, USA).

\section{Results}

Cross-sensitivity of $C L-V 8 B$ to various genotoxic agents. The CL-V8B cell line originates from ENU mutagenized Chinese hamster wild type fibroblasts derived from lungs (V79B). It was isolated at the Department of Toxicogenetics, Leiden University Medical Centre, The Netherlands, on the basis of its hypersensitivity to MMC, using the replica plating method as described previously (25).

The results of clonogenic survival assays (Fig. 1A and B) imply that CL-V8B mutant were significantly more sensitive to crosslinking agents, MMC ( 17-fold) and CDDP ( 7.4-fold) than the parental V79B cell line. MMC is an antibiotic and a powerful bifunctional alkylating agent, forming six covalent DNA adducts (26). The covalent link between two DNA strands (ICLs) interferes with fundamental cellular processes, such as replication and transcription, and is responsible for MMC cytotoxicity. Compared with MMC, cisplatin forms fewer ICLs and a large percentage of intrastrand crosslinks (27). The fact that the CL-V8B mutant is hypersensitive to crosslinking agents, suggests strongly that this cell line has defective ICLs repair. To test whether CL-V8B cells were also sensitive to other genotoxic agents, a series of clonogenic survival assays were conducted.

It was demonstrated that CL-V8B was not sensitive to ultraviolet radiation and oxidative DNA stress caused by $\mathrm{H}_{2} \mathrm{O}_{2}$ (Fig. $1 \mathrm{C}$ and D). However, CL-V8B displayed a moderate-degree sensitivity to agents that interfere with replication forks, e.g. topoisomerase I inhibitor CPT ( 3.2-fold) and HU ( 2.5-fold; Fig. 1E and F, respectively). The distinctive features of the mutant included its $\sim 4$-fold greater sensitivity to BLM (Fig. 1G), a radiomimetic compound associated with formation of single strand breaks (SSBs) and DSBs within DNA, in addition to hypersensitivity to 6-thioguanine ( 3.5-fold; Fig. 1H), an antimetabolite causing DSBs with resultant Rad51 foci formation and repair of these damages through the HR process (2). The cells carrying mutations of various HR genes, e.g. BRCA1/2, RAD51, NBS1 and ATM, are known to be highly sensitive to poly (ADP-ribose) polymerase inhibitors (iPARP) $(3,28)$. Analysis of clonogenic survival of CL-V8B cells treated with a potent PARP inhibitor KU0058948 indicated that mutant was extremely sensitive to this agent ( 430-fold, Fig. 1I). Inhibition of PARP interrupts repair of DNA SSBs by base excision repair and leads to accumulation of these lesions. SSBs are then transformed into DSBs (28). Since DSBs are formed during ICLs removal and repaired via $\mathrm{HR}$, the sensitivity of CL-V8B cells to crosslinking agents is likely linked to impairment of HR.

Complementation of MMC sensitivity. To establish whether CL-V8B belongs to any of previously identified groups of Chinese hamster cell mutants hypersensitive to crosslinking compounds, a genetic complementation analysis was conducted. This method, based on cell fusion combined with clonogenic survival assay, allows it to be established whether a gene defective in one cell line is complemented by proper copy of the same gene from another cell line used to create a hybrid. If the phenotype of the hybrid cells is similar to the wild type, they belong to different complementation groups. CL-V8B cells were fused with all four previously identified Chinese hamster cell lines with established HR defects, in addition to seven other cell mutants sensitive to crosslinking agents (Table I). Representative survival curves for CL-V8B hybrids with cells from various complementation groups and a control hybrid CL-V8BTOR/CL-V8B, all exposed to MMC, are presented on Fig. 2. All analyzed hybrids, apart from the control hybrid created exclusively of CL-V8B cells, exhibited similar sensitivity to MMC as the parental V79B line; this implies that the ICLs repair defect present in CL-V8B was corrected due to fusion with other cells. This points to CL-V8B as a representative of a new previously uncharacterized complementation group of Chinese hamster cell mutants being sensitive to crosslinking agents.

Kinetics of Rad51 foci formation. To determine the status of homologous recombination in CL-V8B, Rad51 foci formation was analyzed subsequent to exposure of the cells to MMC and radiomimetic BLM. Mutations in the majority of HR genes were previously demonstrated to impair Rad51 foci formation $(8,20-22,29,30)$. Monomers of Rad51 recombinase are recruited to stalled replication forks above the DSBs and create nucleoprotein filaments, which are essential for strand invasion during DSBs repair. Presence of the DNA damage-induced Rad51 foci in the nucleus is postulated to be a marker of DSBs repair by homologous recombination (29).

Although the results of clonogenic survival analysis suggested the presence of HR disturbances in CL-V8B, notably, induction of Rad51 foci was observed in these mutant cells subsequent to their exposure to either BLM or MMC (Fig. 3). In contrast, Rad51 foci were not identified in the nuclei of control HR mutant V-C8 cells with defective Brca2/Fancdl genes (Fig. 3B), which 
Table I. Complementation of MMC sensitivity in hybrids of CL-V8B with other Chinese hamster cell mutants representing different complementation groups.

Mutant

irs1

irs $1 \mathrm{SF}$

CL-V4B

$\mathrm{V}-\mathrm{C} 8$

UV40

$\mathrm{V}-\mathrm{H} 4$

CL-V1B, CL-V5B, CL-V101B

UV20

UV41

CL-V8B
Defected gene/pathway

Complementation of MMC sensitivity after fusion with CL-V8B cells

${ }^{\mathrm{a} C o r r e c t i o n ~ o f ~ M M C ~ s e n s i t i v i t y, ~}{ }^{\mathrm{b}}$ unpublished data from clonogenic cell survival tests obtained in the Department of Molecular Cell Genetics, Collegium Medicum in Bydgoszcz, Nicolaus Copernicus University in Torun, Poland and Department of Toxicogenetics, Leiden University Medical Centre, The Netherlands; ${ }^{c}$ lack of correction of MMC sensitivity; ${ }^{d}$ gene mutations were confirmed by sequencing. MMC, mitomycin C.

A

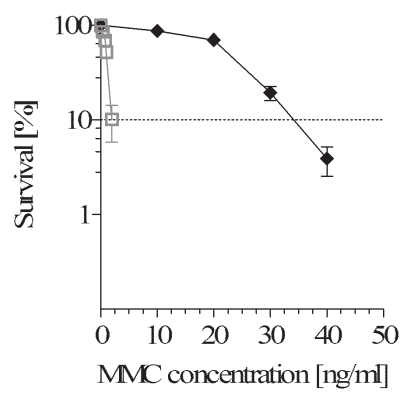

$\mathrm{D}$

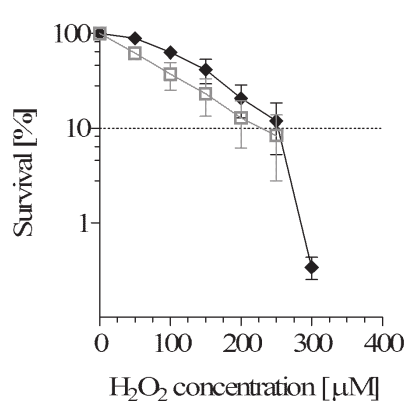

G

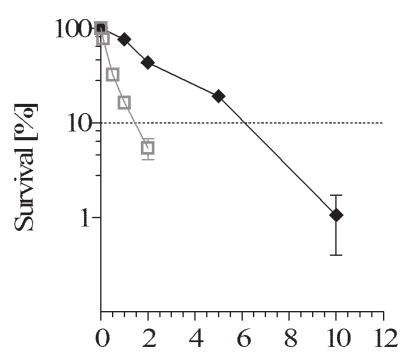

BLMconcetration $[\mu \mathrm{g} / \mathrm{ml}]$
B

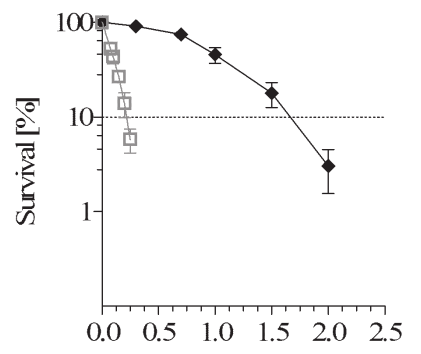

CDDP concentration $[\mu \mathrm{M}]$

E

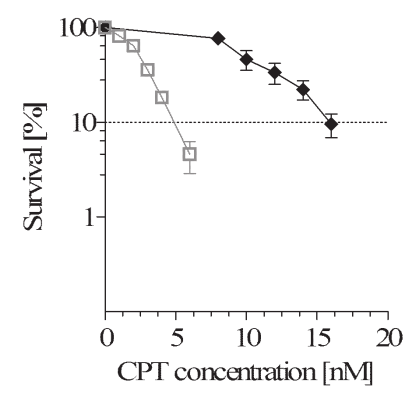

H

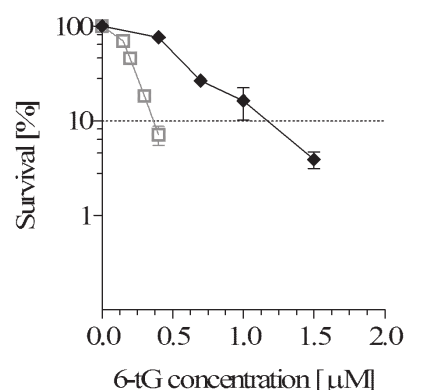

C

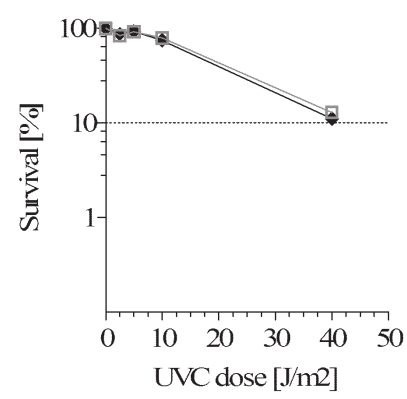

F

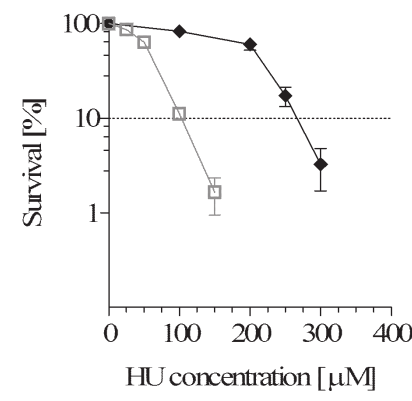

I

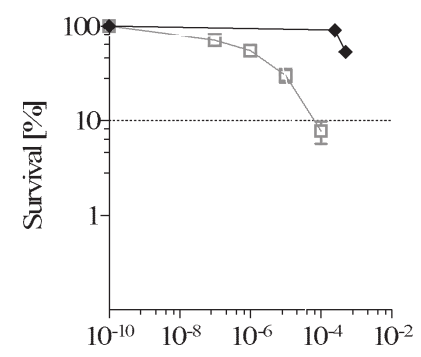

KU0058948 concentration [M]

Figure 1. Clonogenic survival of CL-V8B and the parental cell line V79B following exposure to (A) MMC, (B) CDDP, (C) UVC radiation, (D) hydrogen peroxide, (E) CPT, (F) HU, (G) BLM, (H) 6-tG, (I) poly (adenosine diphosphate-ribose) polymerase inhibitor KU0058948. Data are presented as the mean values from at least three independent experiments. Error bars represent standard error. MMC, mitomycin C; CDDP, cisplatin; CPT, camptothecin; HU, hydroxyurea; BLM, bleomycin; 6-tG, 6-tioguanine. 
A

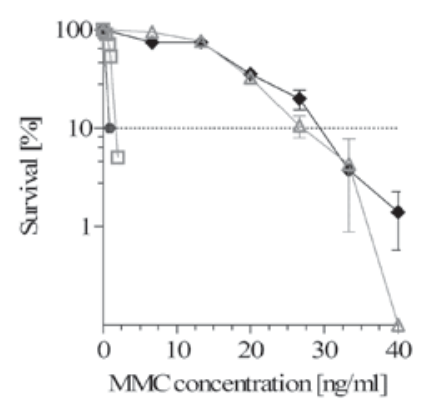

$\mathrm{C}$

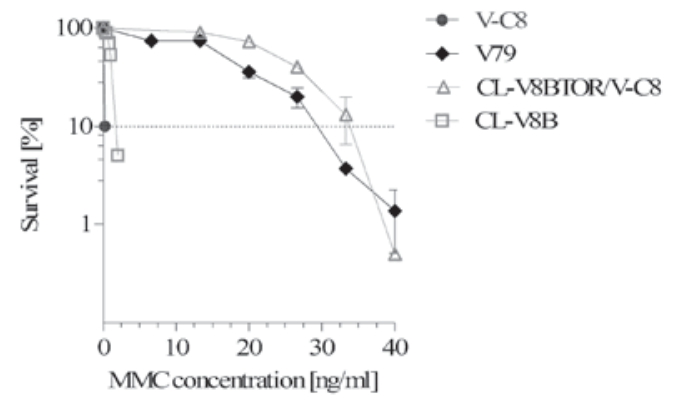

B
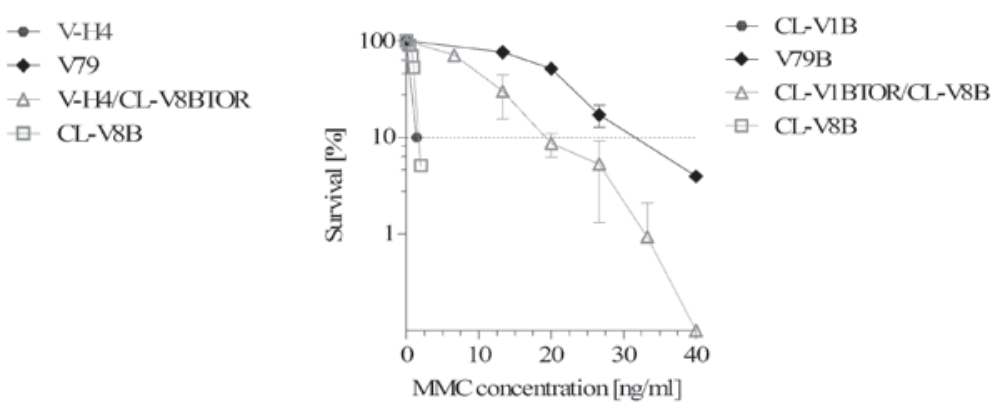

$\mathrm{D}$

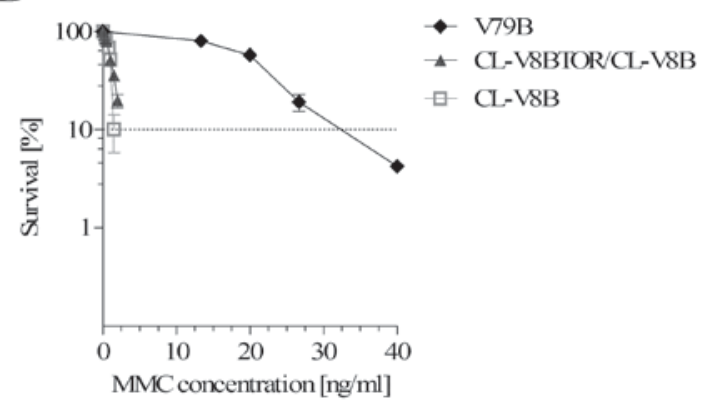

Figure 2. Clonogenic survival of hybrids between CL-V8B and (A) V-H4 (Fanca $\left.{ }^{-/}\right)$, (B) CL-V1B (Fancc $\left.{ }^{-/}\right)$, (C) V-C8 (Brca2/Fancd $\left.1^{-/}\right)$, (D) control hybrid line CL-V8BTOR/CL-V8B treated with MMC. Data represent mean values from at least three independent experiments. Error bars represent standard error. $\mathrm{MMC}$, mitomycin $\mathrm{C}$.
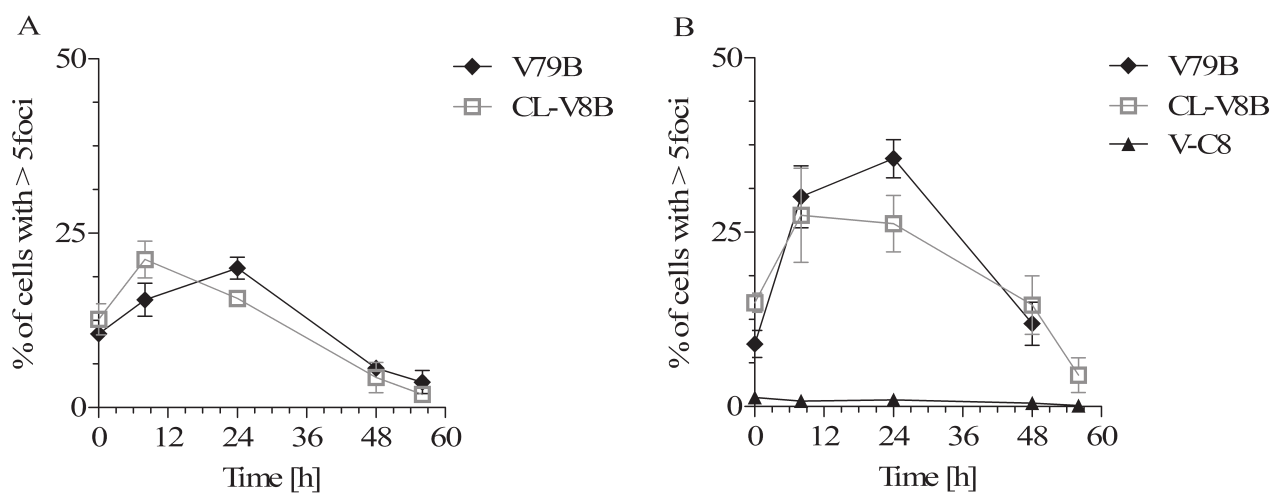

Figure 3. Kinetics of Rad51 foci formation in V79B and CL-V8B cells after (A) BLM and (B) MMC exposure. V-C8 defective in Brca2/Fancd1 (HR and Fanconi anemia pathway) represent control cell line with Rad51 foci impairment. Data represent mean values from at least three independent experiments. Error bars represent standard error. BLM, bleomycin; MMC, mitomycin C; HR, homologous recombination.

is consistent with previously published data (29). The CL-V8B and parental $\mathrm{V} 79 \mathrm{~B}$ cell lines differed marginally regarding their Rad51 foci formation kinetics following treatment with BLM. Although the initial percentage of Rad51 foci-positive cells in both cell lines was similar, the fraction of the positive CL-V8B cells reached its maximum (21.2\%) after $8 \mathrm{~h}$ and then started to decrease, whereas the percentage of the positive V79B cells continued to increase up to $24 \mathrm{~h}$ (20.0\%, Fig. 3A). Following 48 and $60 \mathrm{~h}$, the proportions of Rad51 foci-positive cells decreased below their baseline levels and were again similar for both cell lines. In contrast, exposure to MMC did not alter significantly the kinetics of Rad51 foci formation in the mutant cell line (Fig. 3B). Maximum percentage of CL-V8B cells containing Rad51 foci was reached after $8 \mathrm{~h}(27.4 \%)$ and remained mostly stable up to $24 \mathrm{~h}(26.2 \%)$. In turn, maximum fraction of the positive V79B cells was observed no earlier than after $24 \mathrm{~h} \mathrm{(35.6 \% ).} \mathrm{These} \mathrm{data} \mathrm{imply} \mathrm{that} \mathrm{while} \mathrm{the} \mathrm{formation} \mathrm{of}$ Rad51 foci in CL-V8B cells is generally normal, the kinetics of this process at 8 and $24 \mathrm{~h}$ post-exposure is marginally different than in the parental cells.

Spontaneous and mutagen-induced sister chromatid exchanges. SCEs are a cytological manifestation of DNA brakeage and rejoining. They represent the exchange of 
A
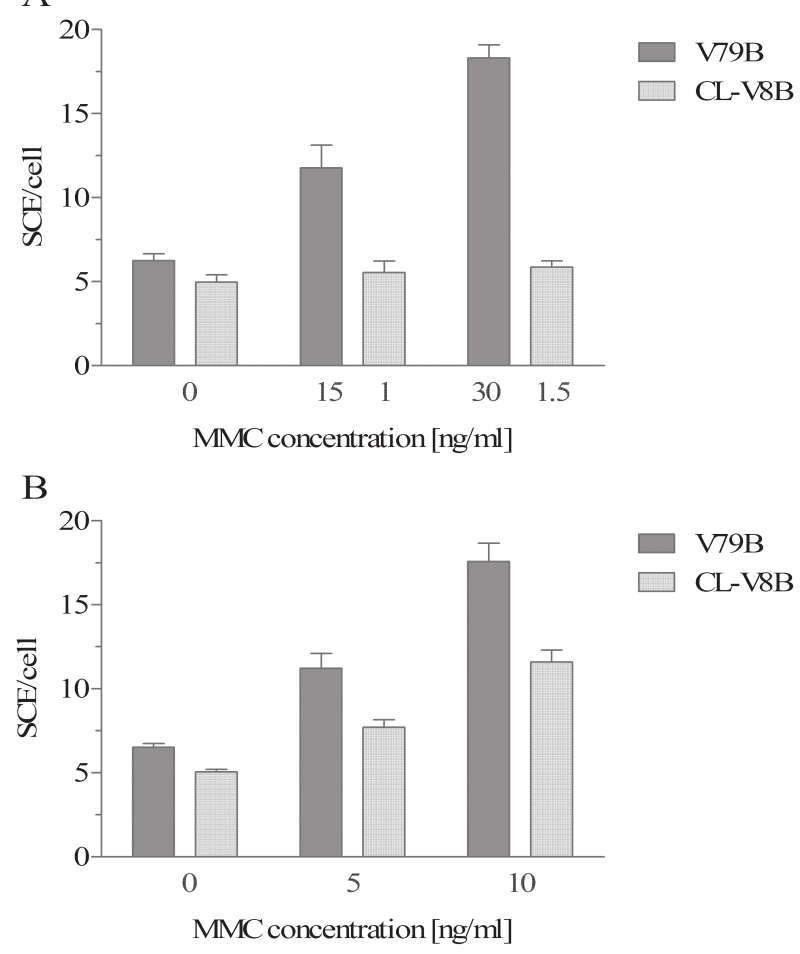

Figure 4. Average number of SCEs in cells exposed to (A) MMC at various concentrations depending on the sensitivity of individual cell lines to this agent, (B) UVC (the same doses for analyzed cell lines). Data represent mean values from at least three independent experiments. Error bars represent standard deviation. SCEs, sister chromatid exchanges; MMC, mitomycin $\mathrm{C}$.

homologous DNA fragments between sister chromatids during physiological processes, including meiosis and replication. SCEs are additionally markers of HR function, since the number of sister chromatid exchanges in cells with defective HR was demonstrated to be lower than in normal cells $(8,21,30-32)$.

To evaluate the efficiency of homologous recombination, the number of SCEs in CL-V8B cells and parental cells exposed to MMC was evaluated. The number of spontaneous SCEs in CL-V8B cells was observed to be marginally lower than in the parental V79B cells $(4.96 \pm 0.44$ and 6.25 \pm 0.4 SCEs per cell, respectively; Fig. 4A). Exposure to MMC, regardless of its concentration, resulted in only a small increase in the

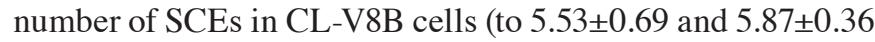
at 1 and $1.5 \mathrm{ng} / \mathrm{ml}$, respectively); in contrast, the number of SCEs in the wild type cells exposed to MMC was markedly higher and increased in a dose-dependent manner (to $11.77 \pm 1.35$ and $18.31 \pm 0.77$ at 15 and $30 \mathrm{ng} / \mathrm{ml}$, respectively). In order to confirm that the variance in the SCEs number did not reflect the differing susceptibility of CL-V8B and $\mathrm{V79B}$ cells to MMC, this parameter was determined after exposure to UVC, a potent inductor of SCEs. Irradiation with 5 and $10 \mathrm{~J} / \mathrm{m}^{2}$ resulted in a marginal increase in the number of SCEs in CL-V8B cells (from $7.7 \pm 0.45$ to $11.62 \pm 0.58$ ), which was markedly lower than in the parental cells (an increase from $11.26 \pm 0.8$ to $17.46 \pm 1.27$; Fig. $4 \mathrm{~B}$ ). This clearly demonstrates that CL-V8B display lower number of MMC- and

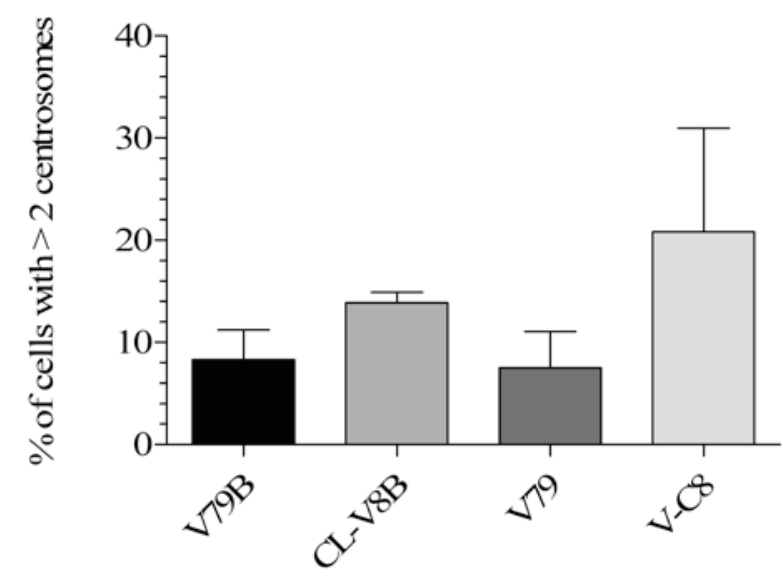

Figure 5. Number of V79B and CL-V8B cells with an abnormal quantity of centrosomes per 100 cells. Data represent mean values from at least three independent experiments. Error bars represent standard error.

UVC-induced SCEs, which indicates a likely impairment of HR process within the mutant cell line.

Centrosome analysis. Centrosomes constitute an organization center of microtubules within the cell. Mutations of HR genes are often associated with abnormalities of centrosomes, and frequently manifest as numeric aberrations, disrupting the cellular role of these structures and leading to genomic instability $(21,33)$. In order to establish whether the defect present in CL-V8B cells affects the number of centrosomes, these organelles were subjected to an immunofluorescent analysis. V-C8 cells with a mutation of the Brca2/Fancdl HR gene and elevated numbers of centrosomes were used as a positive control (21). Immunofluorescent staining indicated that the proportion of CL-V8B cells with an abnormal number of centrosomes was twice as high as in the parental V79B line (21.3 vs. 10.6\%; Fig. 5). Notably, the percentage of the defective cells was similar to that of the V-C8 line. In addition, small labelled structures were identified within CL-V8B cells; these structures may represent numerical or structural abnormalities of centrosomes, e.g. their fragmentation, which may result in the presence of acentriolar centrosomal fragments (acentriolar bodies) acting as additional chromosomes (34). These observations suggest that the defect present in the CL-V8B line affects the number of centrosomes in these cells.

Chromosomal aberrations. Alterations in CL-V8B leading to numerical abnormalities of centrosomes may predispose these cells to genomic instability. Cells with compromised DNA repair often exhibit increased numbers of spontaneous and mutagen-induced CAs $(8,19,21,22)$. It was demonstrated that CL-V8B cells presented with a 1.65 -fold greater number of spontaneous aberrations than the V79B cells $(25.33 \pm 7.64$ and $15.33 \pm 0.58$, respectively) and approximately two-fold greater number of CAs following MMC treatment, regardless of the concentration of this agent (Table II). The key type of spontaneous and MMC-induced CAs in the two cell lines were chromatid gaps, however also chromosomal gaps and 
Table II. Total number of spontaneous and MMC-induced chromosomal aberrations.

\begin{tabular}{lcc}
\hline Cell line & MMC concentration $(\mathrm{ng} / \mathrm{ml})$ & CAs \pm SD \\
\hline V79B & 0 & $15.33 \pm 0.58$ \\
& 45 & $17.33 \pm 5.77$ \\
& 70 & $23.67 \pm 4.62$ \\
CL-V8B & 0 & $25.33 \pm 7.64$ \\
& 2.5 & $32.00 \pm 5.29$ \\
& 5 & $45.33 \pm 1.15$
\end{tabular}

Data represent mean values from at least three independent experiments. Error is represented by SD. MMC, mitomycin C. SD, standard deviation; CAs, chromosomal aberrations.

chromatid breaks were observed with a considerable frequency (Table III). All types of CAs were more prevalent in mutants than in wild type cells, which was particularly evident in the case of chromatid gaps and dicentric chromosomes (Table III). Compared with wild type cells, mutant cells displayed spontaneous and induced CAs following exposure to markedly lower concentrations of MMC. This phenomenon reflected hypersensitivity of CL-V8B to this compound, suggesting that the molecular alteration present in the mutant affects its genomic stability.

Replication analysis by DNA fiber assay. Previous studies suggest that proteins involved in ICLs repair, such as FA and HR, participate in additional processes essential for maintenance of genome stability, such as DNA replication. During this process, DNA repair proteins perform various functions being crucial for stability of replication forks (35-37). The DNA fiber assay allows the establishment of the replication fork velocities and enables various replication structures to be visualized, such as replication fork elongation, initiation of new origins, fork stalling and termination of replication. The replication structures of CL-V8B cells and parental cells were analyzed without their exposure to replication stress and following treatment with hydroxyurea. HU blocks the replication fork due to reduction of the deoxyribonucleotide triphosphate pool, resulting from inhibition of ribonucleotide reductase activity necessary for synthesis of these compounds (38).

Replication fork velocity for both CL-V8B and V79B cells approximated $1 \mathrm{~kb}$ per min $(0.86 \pm 0.24$ and $1.04 \pm 0.13$, respectively). This suggests that the alteration present in CL-V8B does not affect the speed of replication forks. When not exposed to any replication stress, CL-V8B and parental cells differed solely in terms of their type 4 replication structures. Specifically, replication fork stalling in CL-V8B cells occurred markedly less often than in the parental cells. A reduction in the number of this replication structure in the mutant cells correlated with an increase in the number of replication forks being in the process of elongation (i.e. type 1 replication structures, Fig. 6A). However, these differences were not statistically significant. The number of other replication structures was similar in the two cell lines. Notably, although CL-V8B cells are marginally more sensitive to HU than the parental V79B line (Fig. 1F), the results subsequent
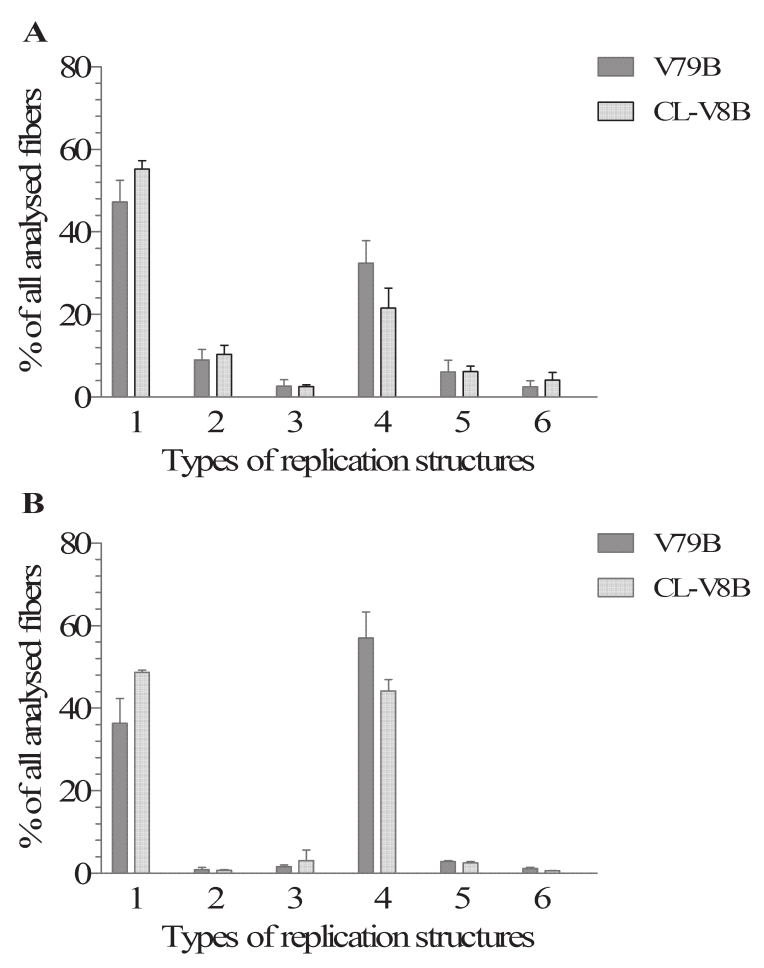

Figure 6. Relative frequency of various replication structures classes in parental V79B and Cl-V8B analyzed in (A) cells with unperturbed replication, (B) after exposure to replication stress generated by hydroxyurea. Bars represent various replication structures: 1 , elongating forks; 2 , origins; 3 , stalled forks; 4, terminated forks; 5 , interspersed fibres; 6, closely spaced origins. Data represent mean values from at least three independent experiments. Error bars represent standard error.

to exposure to this agent were essentially the same as without any replication-stress (Fig. 6B). This suggests that the defect present in the CL-V8B mutant does not affect the efficiency and stabilization of replication forks. However, the differences between CL-V8B and V79B imply that the former may show defects in certain mechanisms responsible for the replication stress signaling.

Cell cycle analysis. Presence of DNA damage within the cell triggers complex damage response pathways, resulting in activation of cell cycle checkpoints, blockade of cell cycle progression, recruitment of repair proteins to the damaged DNA site and induction of apoptosis. The most common type of cell response observed subsequent to exposure to MMC is $\mathrm{S}$-phase arrest, $\mathrm{G}_{2} / \mathrm{M}$-phase delay and increase in the number of apoptotic cells $(39,40)$. Taking into account available data on cell cycle disturbances in HR-deficient cells $(41,42)$ and activation of apoptosis resulting from unrepaired DSBs (43), in addition to the observations indicating the presence of impaired homologous recombination in CL-V8B cells, the effects of $\mathrm{MMC}$ on cell cycle progression were analyzed in these mutant cells and their parental V79B line. Cell cycle progression was analyzed 8,24 and $48 \mathrm{~h}$ subsequent to treatment with 50 and $250 \mathrm{ng} / \mathrm{ml} \mathrm{MMC} \mathrm{(Fig.} 7$ and Tables IV and V).

The alterations in the distribution of V79B cells representing various phases of cell cycle were more evident following their exposure to $250 \mathrm{ng} / \mathrm{ml}$ MMC. A significant 
Table III. Various types of spontaneous and MMC-induced CAs.

\begin{tabular}{|c|c|c|c|c|c|c|}
\hline \multirow[b]{2}{*}{ Type of structural CAs } & \multicolumn{2}{|c|}{ Spontaneous } & \multicolumn{4}{|c|}{ MMC-induced } \\
\hline & V79B & CL-V8B & $\mathrm{V} 79 \mathrm{~B} 45^{\mathrm{a}}$ & CL-V8B $2.5^{\mathrm{a}}$ & V79B $70^{\mathrm{a}}$ & CL-V8B $5^{\mathrm{a}}$ \\
\hline $\operatorname{ctg}$ & $9.00 \pm 1.00$ & $12.33 \pm 3.06$ & $6.00 \pm 2.00$ & $15.33 \pm 3.06$ & $11.67 \pm 3.51$ & $23.67 \pm 3.06$ \\
\hline $\operatorname{csg}$ & $3.00 \pm 3.00$ & $4.33 \pm 2.89$ & $4.00 \pm 2.65$ & $4.33 \pm 1.15$ & $6.33 \pm 2.52$ & $7.67 \pm 3.79$ \\
\hline ctb & $1.33 \pm 0.58$ & $3.67 \pm 1.53$ & $3.00 \pm 1.00$ & $4.00 \pm 1.73$ & $2.33 \pm 2.52$ & $5.67 \pm 1.53$ \\
\hline dic & $0.67 \pm 0.58$ & $3.33 \pm 3.51$ & $1.00 \pm 1.73$ & $6.00 \pm 1.73$ & $1.0 \pm 1.00$ & $5.0 \pm 1.73$ \\
\hline af & $0.67 \pm 0.58$ & $1.00 \pm 1.00$ & $1.67 \pm 1.53$ & $1.33 \pm 0.58$ & $1.33 \pm 1.15$ & $1.33 \pm 1.53$ \\
\hline ci & $0.33 \pm 0.58$ & $0.67 \pm 0.58$ & $0.33 \pm 0.58$ & $0.67 \pm 1.15$ & $0.33 \pm 0.58$ & $1.67 \pm 1.15$ \\
\hline ring & $0.00 \pm 0.00$ & $0.00 \pm 0.00$ & $0.00 \pm 0.00$ & $0.33 \pm 0.58$ & $0.00 \pm 0.00$ & $0.33 \pm 0.58$ \\
\hline
\end{tabular}

${ }^{a} \mathrm{MMC}$ concentrations ( $\left.\mathrm{ng} / \mathrm{ml}\right)$ used to analyze the types of chromosomal aberrations in individual cell lines. Data represent mean values from at least three independent experiments, and values are presented as the mean \pm standard deviation. MMC, mitomycin C; CAs, chromosomal aberrations; ctg, chromatid gaps; csg, chromosomal gaps; ctb, chromatid breaks; dic, dicentric chromosomes; af, acentric fragments; ci, chromatid interchanges; ring, ring chromosomes.

decrease in the percentage of $\mathrm{G}_{1} / \mathrm{G}_{0}$-phase cells was observed $8 \mathrm{~h}$ post-exposure, along with an increase in the fraction of S-phase cells $(\mathrm{P}=2.7 \mathrm{E}-3$; Fig. 7A, left panel). The decrease in the proportion of $\mathrm{G}_{1} / \mathrm{G}_{0}$-phase cells was additionally observed $24 \mathrm{~h}$ post-exposure, reaching statistical significance at $\mathrm{P}=6.8 \mathrm{E}-4$ (Fig. 7B). This was associated with a marginal increase in the proportion of $\mathrm{S}$ - and $\mathrm{G}_{2} / \mathrm{M}$-phase cells, in addition to an increase in the fraction of cells with sub- $\mathrm{G}_{1}$ DNA content, corresponding to fragmentation of DNA at a late stage of apoptosis. $48 \mathrm{~h}$ post-exposure, V79B cells indicated a significant decrease in the proportion of $G_{1} / G_{0}$-phase cells $(\mathrm{P}=1.8 \mathrm{E}-2)$, however the fraction of $\mathrm{S}$-phase cells was markedly lower than at 8 and $24 \mathrm{~h}$ (Fig. 7C). V79B cells were less sensitive to $\mathrm{MMC}$ at $50 \mathrm{ng} / \mathrm{ml}$; exposure to this agent resulted in only minor cell cycle distortion at all analyzed time points, apart from a significant albeit transient $\mathrm{G}_{1} / \mathrm{G}_{0}$-phase delay at $24 \mathrm{~h}(\mathrm{P}=4.0 \mathrm{E}-2$, Fig. 7B, Table IV). A total of $48 \mathrm{~h}$ post-exposure to $50 \mathrm{ng} / \mathrm{ml} \mathrm{MMC}$, the distribution of cells representing various phases of cell cycle was similar to that in non-treated controls.

In the case of the CL-V8B line, severe MMC-induced cell cycle disturbances were observed irrespective of concentration and exposure time. At $8 \mathrm{~h}$ post-exposure, a dose-dependent decrease in the proportion of $\mathrm{G}_{1} / \mathrm{G}_{0}$-phase cells was observed $(\mathrm{P}=8.5 \mathrm{E}-3$ and $\mathrm{P}=1.8 \mathrm{E}-4$ for 50 , and $250 \mathrm{ng} / \mathrm{ml} \mathrm{MMC}$, respectively; Fig. 7A, right panel; Table V) along with an evident $\mathrm{S}$-phase arrest (observed also in parental cells) and a marginal increase in the fraction of $\mathrm{G}_{2} / \mathrm{M}$-phase cells, not observed in V79B. Irrespective of MMC concentration, the percentage of $\mathrm{S}$-phase cells was significantly higher than in untreated cultures $(\mathrm{P}=2.5 \mathrm{E}-2$ and $\mathrm{P}=1.3 \mathrm{E}-4$ for increasing MMC doses). Despite the dose-dependent increase in the proportion of $\mathrm{G}_{2} / \mathrm{M}$-phase cells, the percentage of these cells turned out to be significantly higher than in untreated control cultures only subsequent to exposure to $250 \mathrm{ng} / \mathrm{ml} \mathrm{MMC}$ $(\mathrm{P}=2.1 \mathrm{E}-2)$.

The delay in cell cycle progression was evident $24 \mathrm{~h}$ post-exposure. A significant reduction in the proportion of $\mathrm{G}_{1} / \mathrm{G}_{0}$-phase cells was observed in the CL-V8B cell line exposed to either 50 or $250 \mathrm{ng} / \mathrm{ml}$ MMC $(\mathrm{P}=1.8 \mathrm{E}-5$ and $\mathrm{P}=3.2 \mathrm{E}-9$, respectively). However, in contrast to the V79B line, mutant cells that resumed $S$ phase were arrested at $G_{2} / M$ phase (Fig. 7B). The percentage of cells representing this phase increased with MMC dose ( $\mathrm{P}=4.7 \mathrm{E}-5$ for $50 \mathrm{ng} / \mathrm{ml}$ and $\mathrm{P}=7.3 \mathrm{E}-10$ for $250 \mathrm{ng} / \mathrm{ml}$ ). These changes were accompanied by a dose-dependent increase in the proportion of sub- $G_{1}$ DNA cells, statistically significant for $250 \mathrm{ng} / \mathrm{ml} \mathrm{MMC} \mathrm{(P=4.3E-2).}$

Similar to a previous time point, a significant decrease in the proportion of $\mathrm{G}_{1} / \mathrm{G}_{0}$-phase CL-V8B cells was also observed $48 \mathrm{~h}$ after the $\mathrm{MMC}$ treatment $(\mathrm{P}=1.4 \mathrm{E}-7$ and $\mathrm{P}=2.4 \mathrm{E}-8$ for 50 and $250 \mathrm{ng} / \mathrm{ml} \mathrm{MMC}$, respectively). Furthermore, the mutant exhibited $\mathrm{S}$-phase delay ( $\mathrm{P}=8.6 \mathrm{E}-4$ and $\mathrm{P}=2.4 \mathrm{E}-3$, respectively) and a dose-dependent accumulation of $\mathrm{G}_{2} / \mathrm{M}$-phase cells ( $\mathrm{P}=4.7 \mathrm{E}-2$ and $\mathrm{P}=1.6 \mathrm{E}-3$, respectively); however, the proportion of $\mathrm{G}_{2} / \mathrm{M}$-phase cells was lower than at $24 \mathrm{~h}$ (Fig. 7C). These alterations were accompanied by a significant increase in the fraction of apoptotic cells $(\mathrm{P}=7.1 \mathrm{E}-6$ and $\mathrm{P}=5.1 \mathrm{E}-11$ for 50 and $250 \mathrm{ng} / \mathrm{ml} \mathrm{MMC}$, respectively), not observed in the case of the parental V79B cell line. This implies that the MMC-induced DNA damage in CL-V8B cells was not completely repaired, which resulted in the cell cycle delay and a significant increase in the number of apoptotic cells.

In addition, comparison of percentages of parental V79B and mutant CL-V8B cells representing the same phases of cell cycle following exposure to equal MMC concentrations at identical time points presented with statistically significant differences. Following $8 \mathrm{~h}$, the two cell lines differed in the proportion of $G_{1} / G_{0}$-phase cells for both MMC concentrations $(\mathrm{P}<0.05)$ and in the proportion of $\mathrm{G}_{2} / \mathrm{M}$-phase cells for $250 \mathrm{ng} / \mathrm{ml}(\mathrm{P}<0.05)$. At $24 \mathrm{~h}$, significant differences in the percentages of $G_{1} / G_{0}$ - and $G_{2} / M$-phase cells were observed between the mutant and parental cultures irrespective of MMC concentration $(\mathrm{P}<0.05)$. After $48 \mathrm{~h}$, an increase in the proportion of apoptotic cells and a decrease in the percentage of $\mathrm{G}_{1} / \mathrm{G}_{0}$-phase cells was observed in CL-V8B line exposed to either concentration of $\mathrm{MMC}(\mathrm{P}<0.00001$ and $\mathrm{P}<0.05$, respectively), which distinguished this cell line from the parental one.

\section{Discussion}

CL-V8B represents a new complementation group among Chinese hamster cell mutants hypersensitive to DNA 
A

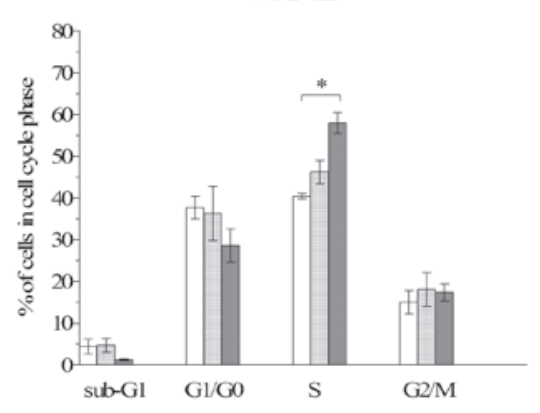

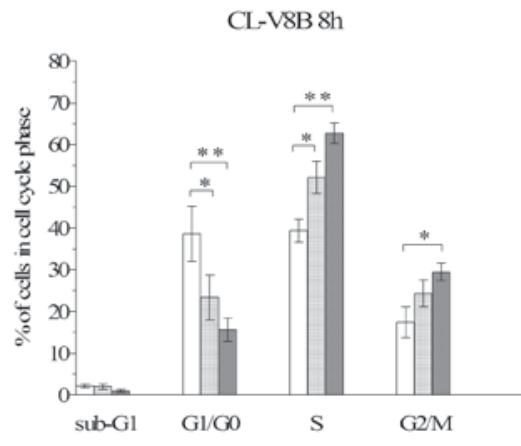

CL-V8B 24h
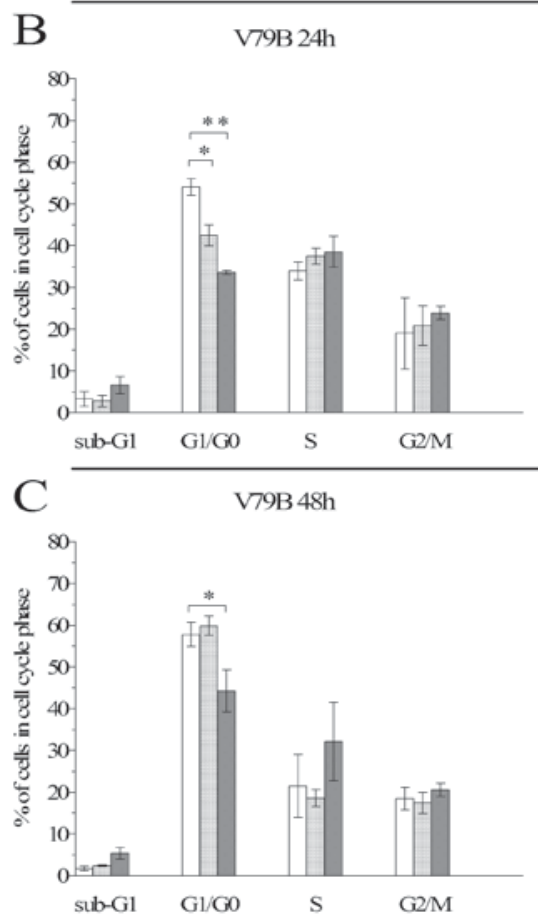

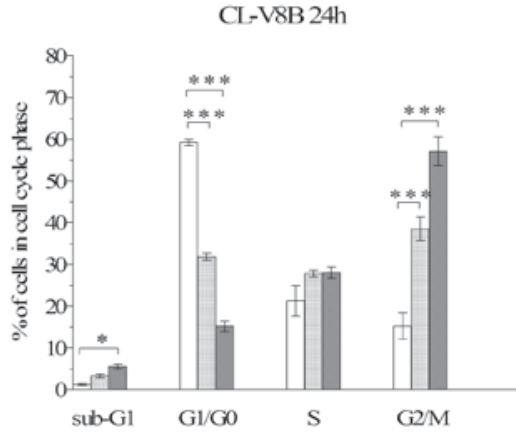

CL-V8B $48 \mathrm{~h}$

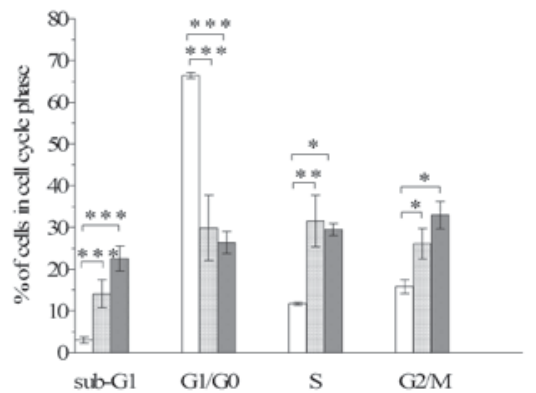

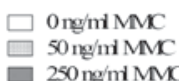

$250 \mathrm{ng} \operatorname{miMMC}$

Figure 7. Cell cycle distribution in parental V79B and CL-V8B cells treated with MMC. Cells were exposed to various concentrations of MMC for (A) 8 h, (B) $24 \mathrm{~h}$ and (C) $48 \mathrm{~h}$. Non-treated cells were used as the control. Bars represent percentages of cells in various phases of cell cycle after MMC exposure, defined on the basis of their DNA contents. Asterisks indicate statistically significant differences between untreated and treated cells from the same cell line $\left({ }^{*} \mathrm{P}<0.05,{ }^{* *} \mathrm{P}<0.001,{ }^{* * *} \mathrm{P}<0.0001\right) . \mathrm{MMC}$, mitomycin $\mathrm{C}$.

crosslinking agents. Aside from increased sensitivity to mitomycin $C(\sim 17$-fold) and cisplatin ( 7.4 -fold $)$, this mutant additionally displayed hypersensitivity to various DNA-damaging agents, which is typical for mutants with defects of the HR and FA pathways. CL-V8B cells demonstrated hypersensitivity to radiomimetic BLM ( 4-fold), also observed in the FA pathway mutant NM3 $\left(\mathrm{Fancg}^{-/}\right)$ and in CL-V4B cells with mutated Rad51C gene, involved in both FA and HR pathways $(8,44)$. This indicates that one of these pathways is compromised in the CL-V8B cell line. Owing their sensitivity to HU ( 2.5-fold) and 6-thioguanine ( $\sim 3.5$-fold), CL-V8B seem to resemble the cells with defected DNA DSBs repair by HR, such as V-C8 cells carrying a biallelic nonsense mutation in Brca2/Fancdl gene $(2,21)$. Another argument for defect in this repair process stems from increased sensitivity of CL-V8B to camptothecin ( 3.2-fold), observed additionally in irs1 $\left(\mathrm{Xrcc}^{\%} \boldsymbol{\gamma}^{-}\right)$and irs3 $\left.\left(\operatorname{Rad} 51 \mathrm{C}^{-}\right)^{-}\right)$, both being HR mutants (45). Additionally, CL-V8B cells exhibited a marked sensitivity to PARP inhibitor ( 430-fold,
Fig. 1I), which is also a specific feature of all Chinese hamster cell lines defective in HR, in addition to human cell lines carrying mutations in BRCA1, BRCA2, RAD51, USP11, ATM, ATR and NBS1 $(3,28,46)$. Chinese hamster mutants, V-C8 (Brca2/Fancdl) and CL-V4B (Rad51C/Fanco), show clear hypersensitivity to PARP inhibitors, up to 1,000-fold greater in the case of Brca2-deficient cells $(28,47)$. Accordingly, PARP inhibition in HR mutants result in accumulation of DSBs, which may lead to cell death (28). In contrast to HR mutants, the sensitivity to iPARP among cells with FA pathway damage, such as FANCD2, FANCA and FANCC, is comparable to that observed in the case of isogenic wild type cells (3). The current study indicated that rodent lines CL-V1B, CL-V5B and CL-V101B carrying mutations of the Fance gene are not sensitive to iPARP (data not shown). The cross-sensitivity profile of CL-V8B cells suggests that the defect inherent to this line most likely involves HR or a part of FA pathway closely interacting with HR proteins, such as PALB2/Fancn, Fancj and the structure-specific 

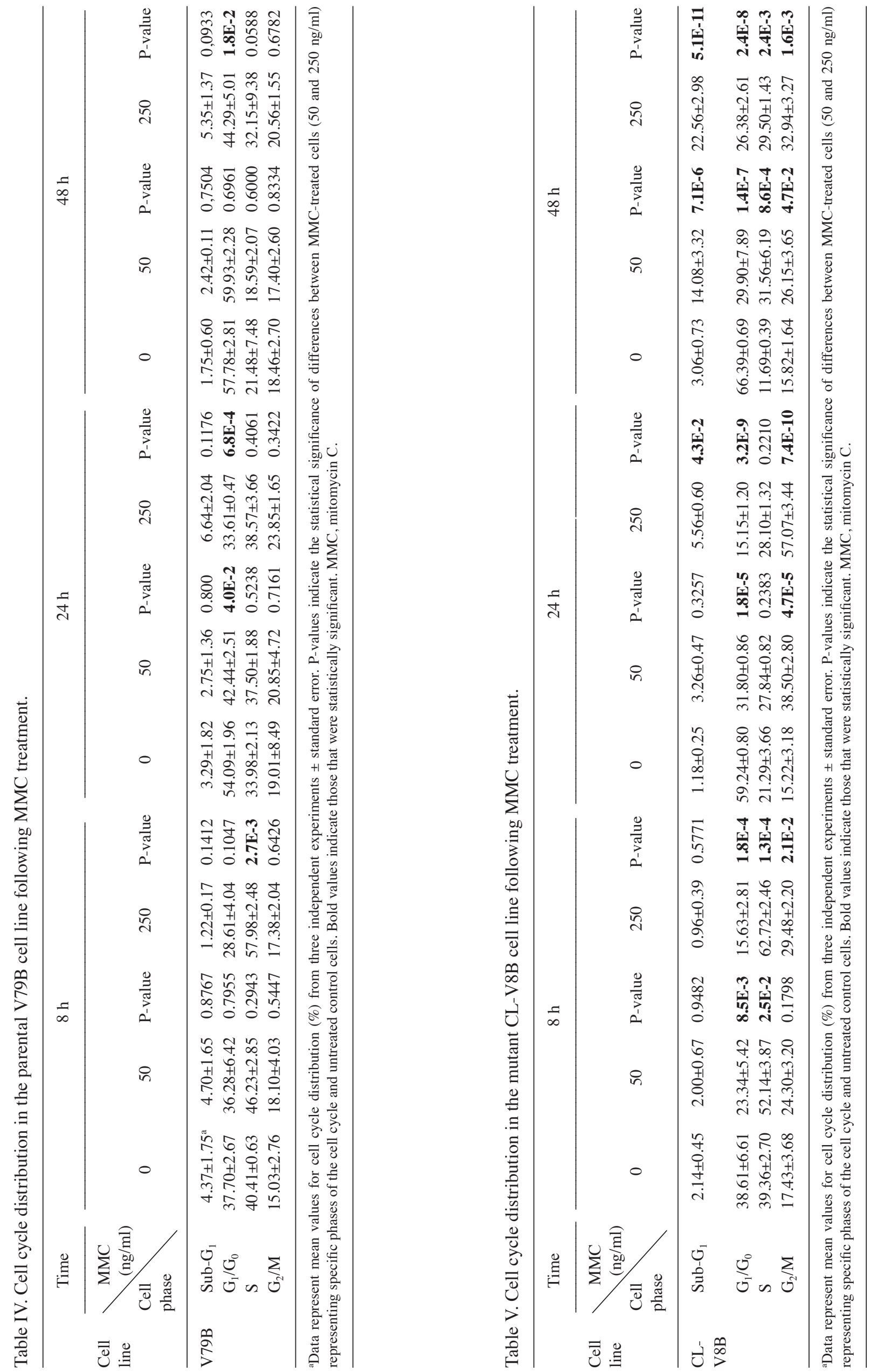
endonuclease subunit gene Slx4. Mutation in the remaining FA genes encoding core and ID complexes in FA pathway were excluded based on examination of Fancd 2 monoubiquitination (data not shown). In addition, the deficiency of NER proteins involved in ICLs repair, Ercc1 and Errc4, whose failure results in hypersensitivity to crosslinking agents, was excluded on the basis of complementation analysis with UV20 $\left(\right.$ Erccl $\left.^{-}\right)$and UV41 (Ercc4\%) mutants (Table I). Another argument for normal function of NER in CL-V8B cells was their insensitivity to UV.

As high sensitivity of CL-V8B cells to iPARP and DNA damaging factors, such as BLM and MMC, indicated potential failure of homologous recombination, a series of experiments was conducted to verify the course of this process. A key step of HR is formation of the Rad51 nucleofilament. Induction of Rad51 foci is impaired in cells with abnormalities of genes encoding $\operatorname{Rad} 51$ and its four paralogs: Rad51C/Fanco, Rad51D, Xrcc2 and Xrcc3, in addition to in cells with defects of Brca2/Fancd1, PALB2/FANCN, DSS1 and $A T M$ genes $(8,20-22,29,30,48-50)$. However, abnormal nucleofilament induction is not observed in cells with certain other mutated HR genes, including Rad52, Rad54, Nbs1 and Uspl1 (46,51,52). Nbsl mutation was demonstrated to be reflected by prolonged presence of Rad51 foci in cell nucleus, and silencing of USP11 resulted in their faster removal, which implies that defective HR may also alter Rad51 kinetics $(46,53)$. Similar changes were observed in the CL-V8B mutant exposed to BLM; these cells were characterized by earlier induction and reached maximum number of Rad51 foci faster than the parental cells (Fig. 3A). It is suggested that unidentified defective proteins present in CL-V8B cells are involved in the formation and stabilization of the Rad51 nucleofilament, however no serious disturbances of this process were observed in the current study. It is also possible that CL-V8B may carry a defective gene encoding a protein involved in DSBs removal, which interacts with Rad51 nucleofilament formation, however serves a principal role at later stages of the repair.

Sister chromatid exchanges take place during restoration of replication after replication fork collapse due to gaps in DNA and presence of DSBs. Mutations in homologous recombination genes reduce the number of SCEs, as presented previously in Chinese hamster HR mutants, V-C8 and CL-V4B $(8,21)$. In addition, rodent cell lines with defective Rad51D and Rad54 demonstrated a considerable decrease in the number of MMC-induced SCEs, despite a normal number of spontaneous exchanges $(30,31,54)$. However, the number of SCEs in HR-defective cells appears to vary depending on their type. Chicken DT40 with disrupted Rad54 and cells with silenced Rad51 and Rad51 paralogs, Rad51C, Rad51D, Xrcc2 and $X r c c 3$, indicated reduced frequency of both spontaneous and MMC-induced SCEs (32). A smaller number of spontaneous SCEs was also observed in yeast cells with mutation of rad52, and DNA damage-associated SCEs were completely abolished in these cells (55). However, mutation in $\mathrm{Nbs} 1 \mathrm{did}$ not exert an effect on the SCEs number (56). It was demonstrated that the frequency of spontaneous SCEs in the CL-V8B line was marginally reduced; however, exposure of these cells to either MMC or UVC resulted in only small changes in the SCEs number, which constitutes another argument for the presence of a HR defect in these mutant cells.
Another characteristic feature of CL-V8B was the increased proportion of cells with numeric abnormalities of centrosomes (Fig. 5). An increase in the number of cells with additional centrosomes was also identified in $\mathrm{V}-\mathrm{C} 8$ cells with defective Brca2/Fancdl gene, human cells carrying mutations in NBS1 and $A T R$, and mouse embryonic stem cells with deletion of the 11th exon in Brcal $(53,57)$. In addition, aside from normally labelled organelles, CL-V8B cells contained small stained structures which may represent fragmented centrosomes. This type of centrosome aberration, typical for cells with abnormalities of Rad51 and its paralogs, was previously observed in other Chinese hamster cell lines, CL-V4B ( $\operatorname{Rad51C^{-}/)}$, irs1 $\left(X_{\left.r c c 2^{-}\right)}\right)$and irs1SF $\left(\mathrm{Xrcc}^{-\digamma}\right)$ (33). Fragmentation of centrosomes is also characteristic for a Chinese hamster ovary cell line with abnormal Rad51 protein, mouse cells with silenced $\operatorname{Rad} 51 D(31,58)$ and human cells with haploinsufficiency of $R A D 51 B$ gene (59). These observations suggest that the defective protein of CL-V8B mutant may serve a role in the maintenance of correct centrosome number. Furthermore, this protein may contribute to stabilization of these organelles, similar to Rad51C, which was also implicated to have such a regulatory role (33). The hypothesis of an association between these two proteins appears to be supported by marginal disturbances in Rad51 foci kinetics observed in CL-V8B cells. Furthermore, abnormalities resulting from insufficient activity of Rad51 and its paralogs are known to result in incorrect formation of the kariokinetic spindle, which in turn leads to chromosome instability (33). The results of the current study are consistent with this data, as an increased number of chromosomal aberrations were observed in CL-V8B cells (Tables II and III). Presumably, aside from involvement in ICLs repair, the defective protein present in this mutant is also necessary for maintaining genomic stability. Although the exact role of the protein impaired in CL-V8B mutant and the mechanism of its action in centrosome stabilization remain unclear, it is suggested that it cooperates with at least one of the HR proteins.

Since proteins of HR and FA pathways, which are crucial for ICLs repair, are additionally involved in replication, this process was analyzed in CL-V8B cells exposed to normal and replication-stress conditions. CL-V8B displayed a moderate degree sensitivity to CPT and HU (Fig. 1E and F), i.e. to the agents that block replication forks and lead to their collapse, respectively. Although the CL-V8B mutant was sensitive to the replication blocking agents and appeared to carry a defect in one of the HR genes, they did not exhibit replication disturbances characteristic of other HR mutants. The non-stress velocity of replication fork in CL-V8B was similar to that observed in wild type cells, whereas cells with mutations of HR genes, including $X r c c 2, X r c c 3$ and $\mathrm{Brca} 2$, are characterized by reduced fork velocity. It is likely that a slower rate of fork progression is associated with activation of specific checkpoints; this slows down the progression of replication forks, protecting them against damage. This effect was demonstrated to correlate with more frequent activation of new origins, which implies that the abovementioned HR proteins are involved both in the control of replication fork speed and in the activation of new origins (35). Although cells with defective ICLs repair present with various phenotypes of replication disturbances, none of them resemble that observed in the CL-V8B mutant $(36,37)$. 
During elongation of DNA strands, CL-V8B cells presented with a greater number of replication forks than the wild type cells, subsequent to treatment with HU (Fig. 6B); although this suggests the potential impairment of mechanisms responsible for DNA damage signaling and fork stalling in CL-V8B cells, this issue requires further elucidation.

Commonly, exposure to MMC results in S-phase arrest, $\mathrm{G}_{2} / \mathrm{M}$-phase delay or increase in the proportion of apoptotic cells $(39,40)$. Activation of checkpoints prevents cell cycle progression and is a prerequisite of ICLs repair and re-entrance of cells to the cycle (41). A total of $8 \mathrm{~h}$ after exposure to MMC, approximately $50-60 \%$ of cells from both CL-V8B and the parental V79B line remained in S-phase, indicating a dose-dependent response to cytostatic conditions (Fig. 7A). In contrast, lack of S-phase arrest following exposure to crosslinking agents was observed in Rad51C- (41) and Brca2/Fancdl-deficient hamster cells (CL-V4B and V-C8, respectively), in addition to primary fibroblasts derived from patients with FA belonging to the complementation group BRCA2/FANCDI $(42,60)$. In addition, ATM- and NBS1-defective cells indicated disturbances in the activation of S-phase checkpoints following exposure to ionizing radiation $(61,62)$. ATM is required for the initiation of HR and DSBs repair and, as demonstrated recently, also for completion of the HR process after formation of the Rad51 nucleofilament (63). Furthermore, ATM was confirmed to be involved in phosphorylation and activation of the S-phase checkpoint following exposure to ionizing radiation (64). The S-phase checkpoint was demonstrated to additionally be inefficient in FA lymphoblasts (from the FANCA-, FANCB- and FANCC-deficient lymphoblasts) that have been damaged with DNA crosslinking agents (65). However, mutations of these genes in CL-V8B line were excluded based on the results of genetic complementation analysis (Table I) and proper Fancd 2 monoubiquitination (not shown). The CL-V8B mutant indicated normal S-phase arrest and formation of Rad51 foci following exposure to DNA-damaging agents (Figs. 3 and 7A); this implies that proteins responsible for initiation of HR and/or Rad51 nucleofilament formation do not contribute to damage of the mutant, which likely occurs at later stages of HR-mediated ICLs repair.

The S-phase arrest observed following treatment of CL-V8B with MMC was associated with a significant dose-dependent increase in the proportion of $\mathrm{G}_{2} / \mathrm{M}$-phase cells, particularly evident $24 \mathrm{~h}$ post-exposure (Fig. 7). Accumulation of $\mathrm{G}_{2} / \mathrm{M}$-phase cells following exposure to crosslinking agents is specific for both FA- and HR-deficient cells from various species $(66,67)$. This phenomenon was also observed in $\mathrm{Brcal}^{\%} \% 53 \%$-deficient mouse embryonic fibroblasts, which indicated time-dependent accumulation of S-phase cells and sustained increase in the proportion of $\mathrm{G}_{2} / \mathrm{M}$-phase cells following MMC treatment (68). Spontaneous $\mathrm{G}_{2} / \mathrm{M}$-phase arrest was also observed in HeLa cells with inhibited expression of other HR proteins, such as RAD51B and RAD51C (67), and in chicken $\operatorname{Rad51D} /$ DT40 cells. It is postulated that the $\mathrm{G}_{2} / \mathrm{M}$-phase arrest results from accumulation of secondary lesions, such as single- and double-strand breaks and gaps, during the first replication round (65), which may be associated with impairment of DNA repair. Treatment with MMC also resulted in an increase in the number of apoptotic CL-V8B cells, especially $48 \mathrm{~h}$ post-exposure
(Fig. 7B and C). These observations are consistent with the results of previous studies which showed that morphological consequences of the MMC-induced apoptosis are observed $48 \mathrm{~h}$ post-exposure (69), and apoptosis of Brca2-deficient $\mathrm{V}-\mathrm{C} 8$ cells starts $24 \mathrm{~h}$ subsequent to DSBs formation (42). Induction of apoptosis in response to DNA damage was also observed in hamster cells with defective HR proteins, such as Xrcc2 and Rad51c, in addition to after exposure to camptothecin. However, contrary to the results of the current study, the apoptotic response of Xrcc2- and Rad51c-deficient cells was similar to that observed in parental V79 or mutant cells corrected for the HR defect (70). Previous studies have indicated that the presence of unrepaired DSBs may result in apoptosis (43) and chromosomal aberrations, such as chromosome breaks (71) or chromatid gaps in the case of unrepaired SSBs (72). Initiation of apoptosis in CL-V8B cells likely resulted from their defects leading to unrepaired DNA breaks; this hypothesis appears to be supported by increased level of CAs (Table II). However, the apoptotic response to DNA damage may also depend on the type of DNA-damaging agent and genetic background of exposed cells. Apoptotic response and $\mathrm{G}_{2} / \mathrm{M}$-phase arrest were lacking in HR-deficient hamster mutant $\mathrm{Xrcc} 3 \%$, however were observed in numerous other HR mutants, in addition to in the Xrcc3-proficient cell line (70). Research on lymphoblastoid FA cell lines has produced inconclusive results, as treatment with MMC either did not induce any apoptotic changes (73) or resulted in $\mathrm{G}_{2} / \mathrm{M}$-phase arrest and accumulation of apoptotic cells (74).

The results of the current study indicate that CL-V8B belongs to a new complementation group of Chinese hamster cell mutants sensitive to crosslinking agents. Phenotypic analysis of CL-V8B suggests that a molecular defect of this mutant contributes to defective DSBs repair. The results of clonogenic survival tests imply that the dysfunctional protein of CL-V8B line is directly associated with HR-related genes or cooperates closely with this DNA repair system. This protein may additionally be involved in the FA pathway and serve a role in DSBs removal during ICLs repair. This hypothesis is supported by the fact that some other proteins, e.g. BRCA2/FANCD1, Rad51C/FANCO and PALB2/FANCN, were demonstrated to be involved in the FA and HR pathways. Furthermore, phenotypic analysis of CL-V8B implies that molecular disturbances present in these cells may be associated with the final stage of DSBs formation. One argument for this hypothesis stems from the fact that no serious alterations in Rad51 nucleofilament formation, a key step of HR process used to verify correct functioning of this repair system, were observed. The unique phenotype of the mutant implies that in contrast to other cells with compromised HR, the CL-V8B line does not demonstrate replication defects. In addition, they have normally functioning S-phase checkpoints, which is not observed in cells with defective HR and in certain mutants with impaired FA.

The genetic background in a small proportion of patients with defective ICLs repair remains unclear, and the majority of biallelic HR mutants are lethal in humans. The unique phenotype of CL-V8B, not observed in any other known Chinese hamster mutants sensitive to DNA crosslinking agents, suggests the presence of a yet to be unidentified defective gene involved in ICL repair. Subsequent to identification of this 
gene, CL-V8B may constitute an interesting cellular model to study the mechanism of DNA crosslink removal.

\section{Acknowledgements}

The present study was supported by the Polish National Science Centre (grant no. N N401 017640). Preliminary results were presented as a poster during the 4th EMBO Meeting Advancing the Life Sciences (September 2012; Nice, France). The authors would like to thank Dr D. Gackowski for assistance with statistical analysis.

\section{References}

1. Bryant HE, Schultz N, Thomas HD, Parker KM, Flower D, Lopez E, Kyle S, Meuth M, Curtin NJ and Helleday T: Specific killing of BRCA2-deficient tumours with inhibitors of poly (ADP-ribose) polymerase. Nature 434: 913-917, 2005.

2. Issaeva N, Thomas HD, Djureinovic T, Jaspers JE, Stoimenov I, Kyle S, Pedley N, Gottipati P, Zur R, Sleeth K, et al: 6-thioguanine selectively kills BRCA2-defective tumors and overcomes PARP inhibitor resistance. Cancer Res 70: 6268-6276, 2010.

3. McCabe N, Turner NC, Lord CJ, Kluzek K, Bialkowska A, Swift S, Giavara S, O'Connor MJ, Tutt AN, Zdzienicka MZ, et al Deficiency in the repair of DNA damage by homologous recombination and sensitivity to poly (ADP-ribose) polymerase inhibition. Cancer Res 66: 8109-8115, 2006.

4. Thompson LH, Brookman KW, Weber CA, Salazar EP, Reardon JT, Sancar A, Deng Z and Siciliano MJ: Molecular cloning of the human nucleotide-excision-repair gene ERCC4 Proc Natl Acad Sci USA 91: 6855-6859, 1994.

5. Weeda G, Hoeijmakers JH and Bootsma D: Genes controlling nucleotide excision repair in eukaryotic cells. Bioessays 15 : 249-258, 1993

6. Thacker J and Zdzienicka MZ: The mammalian XRCC genes: Their roles in DNA repair and genetic stability. DNA Repair (Amst) 2: 655-672, 2003.

7. Rolig RL, Lowery MP, Adair GM and Nairn RS: Characterization and analysis of Chinese hamster ovary cell ERCC1 mutant alleles. Mutagenesis 13: 357-365, 1998.

8. Godthelp BC, Wiegant WW, van Duijn-Goedhart A, Schärer OD, van Buul PP, Kanaar R and Zdzienicka MZ: Mammalian Rad51C contributes to DNA cross-link resistance, sister chromatid cohesion and genomic stability. Nucleic Acids Res 30: 2172-2182, 2002.

9. Vaz F, Hanenberg H, Schuster B, Barker K, Wiek C, Erven V, Neveling K, Endt D, Kesterton I, Autore F, et al: Mutation of the RAD51C gene in a Fanconi anemia-like disorder. Nat Genet 42: 406-409, 2010.

10. Bracalente C, Ibañez IL, Molinari B, Palmieri M, Kreiner A Valda A, Davidson J and Durán H: Induction and persistence of large $\gamma \mathrm{H} 2 \mathrm{AX}$ foci by high linear energy transfer radiation in DNA-dependent protein kinase-deficient cells. Int J Radiat Oncol Biol Phys 87: 785-794, 2013.

11. Maeda J, Bell JJ, Genet SC, Fujii Y, Genet MD, Brents CA, Genik PC and Kato TA: Potentially lethal damage repair in drug arrested G2-phase cells after radiation exposure. Radiat Res 182: 448-457, 2014

12. Deans AJ and West SC: DNA interstrand crosslink repair and cancer. Nat Rev Cancer 11: 467-480, 2011.

13. Jaspers NG, Raams A, Silengo MC, Wijgers N, Niedernhofer LJ, Robinson AR, Giglia-Mari G, Hoogstraten D, Kleijer WJ, Hoeijmakers JH and Vermeulen W: First reported patient with human ERCC1 deficiency has cerebro-oculo-facio-skeletal syndrome with a mild defect in nucleotide excision repair and severe developmental failure. Am J Hum Genet 80: 457-466, 2007.

14. Vrouwe MG, Elghalbzouri-Maghrani E, Meijers M, Schouten P, Godthelp BC, Bhuiyan ZA, Redeker EJ, Mannens MM, Mullenders LH, Pastink A and Darroudi F: Increased DNA damage sensitivity of Cornelia de Lange syndrome cells: Evidence for impaired recombinational repair. Hum Mol Genet 16: 1478-1487, 2007.

15. van der LP, Oostra AB, Rooimans MA, Joenje H and de Winter JP: Diagnostic overlap between fanconi anemia and the cohesinopathies: Roberts syndrome and warsaw breakage syndrome. Anemia 2010: 565268, 2010
16. Kim H and D'Andrea AD: Regulation of DNA cross-link repair by the Fanconi anemia/BRCA pathway. Genes Dev 26: 1393-1408, 2012.

17. Wong MW, Nordfors C, Mossman D, Pecenpetelovska G, Avery-Kiejda KA, Talseth-Palmer B, Bowden NA and Scott RJ: BRIP1, PALB2, and RAD51C mutation analysis reveals their relative importance as genetic susceptibility factors for breast cancer. Breast Cancer Res Treat 127: 853-859, 2011.

18. Liu J and Krantz ID: Cornelia de Lange syndrome, cohesin, and beyond. Clin Genet 76: 303-314, 2009.

19. Zdzienicka MZ, Arwert F, Neuteboom I, Rooimans M and Simons JW: The Chinese hamster V79 cell mutant V-H4 is phenotypically like Fanconi anemia cells. Somat Cell Mol Genet 16: 575-581, 1990.

20. Bishop DK, Ear U, Bhattacharyya A, Calderone C, Beckett M, Weichselbaum RR and Shinohara A: Xrcc3 is required for assembly of Rad51 complexes in vivo. J Biol Chem 273: 21482-21488, 1998.

21. Kraakman-van der Zwet M, Overkamp WJ, van Lange RE, Essers J, van Duijn-Goedhart A, Wiggers I, Swaminathan S, van Buul PP, Errami A, Tan RT, et al: Brca2 (XRCC11) deficiency results in radioresistant DNA synthesis and a higher frequency of spontaneous deletions. Mol Cell Biol 22: 669-679, 2002.

22. O'Regan P, Wilson C, Townsend S and Thacker J: XRCC2 is a nuclear RAD51-like protein required for damage-dependent RAD51 focus formation without the need for ATP binding. J Biol Chem 276: 22148-22153, 2001.

23. Zdzienicka MZ, Jaspers NG, van der Schans GP, Natarajan AT and Simons JW: Ataxia-telangiectasia-like Chinese hamster V79 cell mutants with radioresistant DNA synthesis, chromosomal instability, and normal DNA strand break repair. Cancer Res 49: 1481-1485, 1989.

24. Jackson DA and Pombo A: Replicon clusters are stable units of chromosome structure: Evidence that nuclear organization contributes to the efficient activation and propagation of $\mathrm{S}$ phase in human cells. J Cell Biol 140: 1285-1295, 1998.

25. Zdzienicka MZ and Simons JW: Mutagen-sensitive cell lines are obtained with a high frequency in V79 Chinese hamster cells. Mutat Res 178: 235-244, 1987.

26. Bargonetti J, Champeil E and Tomasz M: Differential toxicity of DNA adducts of mitomycin C. J Nucleic Acids 2010: pii: 698960, 2010.

27. Rabik CA and Dolan ME: Molecular mechanisms of resistance and toxicity associated with platinating agents. Cancer Treat Rev 33: 9-23, 2007.

28. Farmer H, McCabe N, Lord CJ, Tutt AN, Johnson DA, Richardson TB, Santarosa M, Dillon KJ, Hickson I, Knights C, et al: Targeting the DNA repair defect in BRCA mutant cells as a therapeutic strategy. Nature 434: 917-921, 2005.

29. Godthelp BC, Artwert F, Joenje H and Zdzienicka MZ: Impaired DNA damage-induced nuclear Rad51 foci formation uniquely characterizes Fanconi anemia group D1. Oncogene 21: 5002-5005, 2002.

30. Hinz JM, Tebbs RS, Wilson PF, Nham PB, Salazar EP, Nagasawa H, Urbin SS, Bedford JS and Thompson LH: Repression of mutagenesis by Rad51D-mediated homologous recombination. Nucleic Acids Res 34: 1358-1368, 2006.

31. Smiraldo PG, Gruver AM, Osborn JC and Pittman DL: Extensive chromosomal instability in Rad51d-deficient mouse cells. Cancer Res 65: 2089-2096, 2005.

32. Sonoda E, Sasaki MS, Morrison C, Yamaguchi-Iwai Y, Takata M and Takeda S: Sister chromatid exchanges are mediated by homologous recombination in vertebrate cells. Mol Cell Biol 19: 5166-5169, 1999.

33. Renglin Lindh A, Schultz N, Saleh-Gohari N and Helleday T: RAD51C (RAD51L2) is involved in maintaining centrosome number in mitosis. Cytogenet Genome Res 116: 38-45, 2007.

34. Nigg EA: Centrosome aberrations: Cause or consequence of cancer progression? Nat Rev Cancer 2: 815-825, 2002.

35. Henry-Mowatt J, Jackson D, Masson JY, Johnson PA, Clements PM, Benson FE, Thompson LH, Takeda S, West SC and Caldecott KW: XRCC3 and Rad51 modulate replication fork progression on damaged vertebrate chromosomes. Mol Cell 11: 1109-1117, 2003.

36. Schwab RA, Blackford AN and Niedzwiedz W: ATR activation and replication fork restart are defective in FANCM-deficient cells. EMBO J 29: 806-818, 2010.

37. Schwab RA, Nieminuszczy J, Shin-ya K and Niedzwiedz W: FANCJ couples replication past natural fork barriers with maintenance of chromatin structure. J Cell Biol 201: 33-48, 2013. 
38. Koc A, Wheeler LJ, Mathews CK and Merrill GF: Hydroxyurea arrests DNA replication by a mechanism that preserves basal dNTP pools. J Biol Chem 279: 223-230, 2004.

39. Mladenov E, Tsaneva I and Anachkova B: Activation of the S phase DNA damage checkpoint by mitomycin C. J Cell Physiol 211: 468-476, 2007.

40. Kang SG, Chung H, Yoo YD, Lee JG, Choi YI and Yu YS: Mechanism of growth inhibitory effect of Mitomycin-C on cultured human retinal pigment epithelial cells: Apoptosis and cell cycle arrest. Curr Eye Res 22: 174-181, 2001

41. Somyajit K, Subramanya S and Nagaraju G: Distinct roles of FANCO/RAD51C protein in DNA damage signaling and repair: Implications for Fanconi anemia and breast cancer susceptibility. J Biol Chem 287: 3366-3380, 2012.

42. Rocca CJ, Soares DG, Bouzid H, Henriques JA, Larsen AK and Escargueil AE: BRCA2 is needed for both repair and cell cycle arrest in mammalian cells exposed to S23906, an anticancer monofunctional DNA binder. Cell Cycle 14: 2080-2090, 2015.

43. Kaina B: DNA damage-triggered apoptosis: Critical role of DNA repair, double-strand breaks, cell proliferation and signaling. Biochem Pharmacol 66: 1547-1554, 2003.

44. Wilson JB, Johnson MA, Stuckert AP, Trueman KL, May S, Bryant PE, Meyn RE, D'Andrea AD and Jones NJ: The Chinese hamster FANCG/XRCC9 mutant NM3 fails to express the monoubiquitinated form of the FANCD2 protein, is hypersensitive to a range of DNA damaging agents and exhibits a normal level of spontaneous sister chromatid exchange. Carcinogenesis 22: 1939-1946, 2001

45. Jones NJ, Ellard S, Waters R and Parry EM: Cellular and chromosomal hypersensitivity to DNA crosslinking agents and topoisomerase inhibitors in the radiosensitive Chinese hamster irs mutants: Phenotypic similarities to ataxia telangiectasia and Fanconi's anaemia cells. Carcinogenesis 14: 2487-2494, 1993.

46. Wiltshire TD, Lovejoy CA, Wang T, Xia F, O'Connor MJ and Cortez D: Sensitivity to poly (ADP-ribose) polymerase (PARP) inhibition identifies ubiquitin-specific peptidase 11 (USP11) as a regulator of DNA double-strand break repair. J Biol Chem 285: 14565-14571, 2010.

47. Somyajit K, Mishra A, Jameei A and Nagaraju G: Enhanced non-homologous end joining contributes toward synthetic lethality of pathological RAD51C mutants with poly (ADP-ribose) polymerase. Carcinogenesis 36: 13-24, 2015.

48. Yuan SS, Chang HL and Lee EY: Ionizing radiation-induced Rad51 nuclear focus formation is cell cycle-regulated and defective in both $\mathrm{ATM}^{(--)}$and c-Abl ${ }^{(--)}$cells. Mutat Res 525 85-92, 2003.

49. Gudmundsdottir K, Lord CJ, Witt E, Tutt AN and Ashworth A: DSS1 is required for RAD51 focus formation and genomic stability in mammalian cells. EMBO Rep 5: 989-993, 2004.

50. Xia B, Dorsman JC, Ameziane N, de Vries Y, Rooimans MA Sheng Q, Pals G, Errami A, Gluckman E, Llera J, et al: Fanconi anemia is associated with a defect in the BRCA2 partner PALB2. Nat Genet 39: 159-161, 2007.

51. Dong Z, Zhong Q and Chen PL: The Nijmegen breakage syndrome protein is essential for Mre11 phosphorylation upon DNA damage. J Biol Chem 274: 19513-19516, 1999.

52. van Veelen LR, Essers J, van de Rakt MW, Odijk H, Pastink A, Zdzienicka MZ, Paulusma CC and Kanaar R: Ionizing radiation-induced foci formation of mammalian Rad51 and Rad54 depends on the Rad51 paralogs, but not on Rad52. Mutat Res 574: 34-49, 2005.

53. Shimada M, Sagae R, Kobayashi J, Habu T and Komatsu K: Inactivation of the Nijmegen breakage syndrome gene leads to excess centrosome duplication via the ATR/BRCA1 pathway. Cancer Res 69: 1768-1775, 2009.

54. Dronkert ML, Beverloo HB, Johnson RD, Hoeijmakers JH, Jasin M and Kanaar R: Mouse RAD54 affects DNA double-strand break repair and sister chromatid exchange. Mol Cell Biol 20: $3147-3156,2000$

55. Dong $\mathrm{Z}$ and Fasullo M: Multiple recombination pathways for sister chromatid exchange in Saccharomyces cerevisiae: Role of RAD1 and the RAD52 epistasis group genes. Nucleic Acids Res 31: 2576-2585, 2003.

56. Brugmans L, Verkaik NS, Kunen M, van Drunen E, Williams BR, Petrini JH, Kanaar R, Essers J and van Gent DC: NBS1 cooperates with homologous recombination to counteract chromosome breakage during replication. DNA Repair (Amst) 8: 1363-1370, 2009.
57. Xu X, Weaver Z, Linke SP, Li C, Gotay J, Wang XW, Harris CC, Ried T and Deng CX: Centrosome amplification and a defective G2-M cell cycle checkpoint induce genetic instability in BRCA1 exon 11 isoform-deficient cells. Mol Cell 3: 389-395, 1999.

58. Bertrand P, Lambert S, Joubert C and Lopez BS: Overexpression of mammalian Rad51 does not stimulate tumorigenesis while a dominant-negative Rad51 affects centrosome fragmentation, ploidy and stimulates tumorigenesis, in p53-defective $\mathrm{CHO}$ cells. Oncogene 22: 7587-7592, 2003

59. Date O, Katsura M, Ishida M, Yoshihara T, Kinomura A, Sueda T and Miyagawa K: Haploinsufficiency of RAD51B causes centrosome fragmentation and aneuploidy in human cells. Cancer Res 66: 6018-6024, 2006.

60. Godthelp BC, van Buul PP, Jaspers NG, Elghalbzouri-Maghrani E, van Duijn-Goedhart A, Arwert F, Joenje $\mathrm{H}$ and Zdzienicka MZ: Cellular characterization of cells from the Fanconi anemia complementation group, FA-D1/BRCA2. Mutat Res 601: 191-201, 2006.

61. Beamish H, Williams R, Chen P and Lavin MF: Defect in multiple cell cycle checkpoints in ataxia-telangiectasia postirradiation. J Biol Chem 271: 20486-20493, 1996.

62. Eggleston A: Convergence of DNA repair and cell-cycle checkpoint control. Nat Cell Biol 2: E95, 2000.

63. Bakr A, Oing C, Köcher S, Borgmann K, Dornreiter I, Petersen C, Dikomey E and Mansour WY: Involvement of ATM in homologous recombination after end resection and RAD51 nucleofilament formation. Nucleic Acids Res 43: 3154-3166, 2015.

64. Zhao S, Weng YC, Yuan SS, Lin YT, Hsu HC, Lin SC, Gerbino E, Song MH, Zdzienicka MZ, Gatti RA, et al: Functional link between ataxia-telangiectasia and Nijmegen breakage syndrome gene products. Nature 405: 473-477, 2000.

65. Sala-Trepat M, Rouillard D, Escarceller M, Laquerbe A, Moustacchi E and Papadopoulo D: Arrest of S-phase progression is impaired in Fanconi anemia cells. Exp Cell Res 260: 208-215, 2000.

66. Heinrich MC, Hoatlin ME, Zigler AJ, Silvey KV, Bakke AC, Keeble WW, Zhi Y, Reifsteck CA, Grompe M, Brown MG, et al: DNA cross-linker-induced G2/M arrest in group C Fanconi anemia lymphoblasts reflects normal checkpoint function. Blood 91: 275-287, 1998.

67. Rodrigue A, Coulombe Y, Jacquet K, Gagné JP, Roques C, Gobeil S, Poirier G and Masson JY: The RAD51 paralogs ensure cellular protection against mitotic defects and aneuploidy. J Cell Sci 126: 348-359, 2013.

68. Yun J, Zhong Q, Kwak JY and Lee WH: Hypersensitivity of Brcal-deficient MEF to the DNA interstrand crosslinking agent mitomycin $\mathrm{C}$ is associated with defect in homologous recombination repair and aberrant S-phase arrest. Oncogene 24: 4009-4016, 2005.

69. Pirnia F, Schneider E, Betticher DC and Borner MM: Mitomycin $\mathrm{C}$ induces apoptosis and caspase- 8 and -9 processing through a caspase-3 and Fas-independent pathway. Cell Death Differ 9: 905-914, 2002

70. Hinz JM, Helleday T and Meuth M: Reduced apoptotic response to camptothecin in $\mathrm{CHO}$ cells deficient in XRCC3. Carcinogenesis 24: 249-253, 2003.

71. Bryant PE: The signal model: A possible explanation for the conversion of DNA double-strand breaks into chromatid breaks. Int J Radiat Biol 73: 243-251, 1998.

72. Parshad R, Sanford KK and Jones GM: Chromatid damage induced by fluorescent light during G2 phase in normal and Gardner syndrome fibroblasts. Interpretation in terms of deficient DNA repair. Mutat Res 151: 57-63, 1985.

73. Rey JP, Scott R and Müller H: Apoptosis is not involved in the hypersensitivity of Fanconi anemia cells to mitomycin C. Cancer Genet Cytogenet 75: 67-71, 1994.

74. Kruyt FA, Dijkmans LM, van den Berg TK and Joenje $\mathrm{H}$ Fanconi anemia genes act to suppress a cross-linker-inducible p53-independent apoptosis pathway in lymphoblastoid cell lines. Blood 87: 938-948, 1996 